\title{
Cash Transfers and Fertility: How the Introduction and Cancellation of a Child Benefit Affected Births and Abortions
}

February 2021

\author{
Libertad González ${ }^{1}$ \\ Sofia Karina Trommlerová ${ }^{2}$ \\ (Universitat Pompeu Fabra and Barcelona GSE) \\ (Universitat Pompeu Fabra)
}

\begin{abstract}
Data Availability Statement:
The data used in this article can be obtained from the website of the Spanish statistical office INE (https://www.ine.es/dyngs/INEbase/es/operacion.htm?c=Estadistica_C\&cid=1254736177007\&m $\underline{\text { enu}}=$ resultados $\& \operatorname{secc}=1254736195443 \& i d p=1254735573002$ ). Additional replication materials are provided in the Online Appendix.
\end{abstract}

\section{Disclosure Statement:}

Funding Organizations: This project was funded by ERC Consolidator grant 770958.

Support: Libertad González received ERC Consolidator grant 770958 in 2018.

Positions: No positions to disclose.

Relatives/Partners: Nothing to disclose.

Review of the Work: No other party had the right to review this paper prior to its circulation.

Institutional Review Board (IRB) Approval: No approval was needed since administrative, anonymized data were used.

\footnotetext{
${ }^{1}$ Libertad González is an associate professor of economics at Universitat Pompeu Fabra and the Barcelona Graduate School of Economics.

${ }^{2}$ Sofia Karina Trommlerová is a postdoctoral researcher in economics at Universitat Pompeu Fabra in Barcelona, Spain. Email: sofia.trommlerova@iheid.ch
} 


\begin{abstract}
We study the impact of a universal child benefit on fertility, identifying separately the effects driven by conceptions and those by abortions, and analyzing the potentially asymmetric impact of the benefit's introduction and its later cancellation. We focus on a generous lump-sum maternity allowance that was introduced in Spain in 2007 and then eliminated in 2010. Using administrative, population-level data, we create a panel data set of the 50 Spanish provinces, with monthly data on birth rates and weekly data on abortion rates between 2000 and 2017. Our identification is based on the timing of the introduction and cancellation of the policy (both announcement and implementation), from which we infer when the changes in births and abortions can be expected. We find that the introduction of the policy led to a $3 \%$ increase in birth rates, due to both a decrease in abortions and an increase in conceptions. The announcement of the cancellation led to a transitory increase in birth rates just before the benefit termination was implemented, driven by a short-term decrease in abortions. The actual cancellation then led to a $6 \%$ decline in birth rates. A heterogeneity analysis suggests that the positive fertility effect of the benefit's introduction was driven by high-skilled parents, while the negative impact of the cancellation was larger among low-skilled and out-of-labor-force parents, and in poorer regions and areas that were more affected by the 2008 recession. We also find suggestive evidence that the child benefit had both a timing ("tempo") effect, such that some women had children earlier, and a level ("quantum") effect, where some women had more children than they would have had otherwise.
\end{abstract}

JEL Codes: J13, J18

Keywords: fertility, abortion, birth rate, policy evaluation, child benefit

Acknowledgements: We thank conference participants at the 2019 annual meetings of the Society of Economics of the Household (SEHO) and the European Society of Population Economics (ESPE) for their comments. We also express our gratitude to the attendees of the Applied Lunch seminar at Universitat Pompeu Fabra. We acknowledge funding from the European Research Council (ERC) under the European Union's Horizon 2020 research and innovation programme CoG770958. We appreciate the excellent research assistance provided by Ana Costa-Ramón and Sofia Sierra, and help with the data offered by Laia Ferrer. We are grateful to two anonymous referees for their thoughtful feedback. 


\section{Introduction}

All OECD countries have subsidies that target families with young children, spending on average $2.4 \%$ of their GDP on family benefits (OECD Family Database 2019). The goal of these subsidies is typically to promote fertility, and to ensure a minimum standard of living for all children. Demonstrating their effectiveness in achieving these goals has, however, been challenging.

To this end, we study the impact of a universal child benefit on fertility, identifying separately the effects driven by conceptions and those by abortions. We also explore potential asymmetric effects of the benefit's introduction and its later cancellation. Specifically, we use administrative, population-level data covering all births and abortions in Spain between 2000 and 2017, to examine a generous lump-sum maternity allowance introduced in 2007 and then eliminated in 2010. Our identification is based on exploiting the timing of the introduction and the cancellation of the policy, paying careful attention to announcement and implementation dates, from which we infer when the subsequent effects on births and abortions can be expected.

Relative to the previous literature, this is the first study to analyze the effects on fertility of both the introduction and cancellation of a relatively large cash benefit (maternity allowance). We do so with high-quality administrative microdata on both births and abortions. Abortion data such as that employed here are rare, and crucially allow us to distinguish changes in fertility driven by conceptions versus pregnancy interruptions, a previously understudied channel. We are furthermore able to test predictions from economic theory regarding effect heterogeneity. In particular, we expect the fertility effects to be driven by lower-income women, and the cancellation effects to be stronger than those of the benefit's introduction.

The previous literature has studied both income and price effects on fertility. In Becker's basic model of fertility (Becker 1960), families choose how much to consume and how many children 
to have, while also facing a budget constraint. One might ask how fertility would react to increases in household income (the "income effect"), or how it might change when the price (or cost) of children declines (the "price effect"). The introduction of the child benefit in Spain can be viewed as a reduction in the "price" of children (since its receipt was conditional on having a child).

With respect to the price effect, we contribute to a recent body of work that attempts to estimate the causal effect of direct birth-related cash transfers on fertility, exploiting natural experiments in several different countries (Milligan 2005; Cohen, Dehejia, and Romanov 2013; González 2013; Riphahn and Wiynck 2017). These studies find evidence consistent with a positive and significant price effect on overall fertility, with benefit elasticities around 1-2\%.

Our paper also relates to studies documenting the effects of tax incentives on fertility (Moffitt 1998; Rosenzweig 1999; Baughman and Dickert-Conlin 2003 and 2009; Kearney 2004; Brewer, Ratcliffe, and Smith 2012), as well as research on the fertility effects of other family policies, such as parental leave benefits (Lalive and Zweimüller 2009; Cygan-Rehm 2016; Malkova 2018; Raute 2019). Olivetti and Petrongolo (2017) provide a survey of this literature.

González (2013) evaluates the introduction of this same universal child benefit in Spain, finding an increase in births during the first years of the policy (2007-2009), in part driven by a decrease in abortions right after its announcement. Here, we extend González's (2013) results by evaluating the total effect of this child subsidy (which was cancelled in 2010). Specifically, we study potential asymmetry of the introduction and cancellation effects, examine heterogeneous responses among different types of households, and assess the policy effects on the timing of births ("tempo" effect) and their overall number ("quantum" effect).

We also contribute to the literature addressing the effects of income on fertility. Becker (1960) argues that children are "normal" goods. However, correlational evidence shows that fertility is 
lower in higher-income countries, as well as in richer households within a country (Schultz 2007; Price 2013; UNFPA 2018). A number of papers have attempted to identify the causal effect of income on fertility, following a quasi-experimental approach with data from the United States. Lindo (2010) finds that a husband's job loss reduces total fertility, while Black et al. (2013) show that an exogenous positive shock to men's income increases fertility. Lovenheim and Mumford (2013) also observe positive effects of shocks to housing wealth on fertility. Recall, as discussed above, that we are identifying a price effect, not a pure income effect, since the income shock generated by the benefit is conditional on having a child.

We argue that the specific way in which the child benefit was introduced in Spain in 2007, and subsequently cancelled in 2010 , creates a natural experiment that enables us to study the impact of a transitory, unanticipated income shock (a generous lump-sum "maternity bonus," conditional on childbirth) on fertility. In a national speech on July 3, 2007, the Spanish prime minister unexpectedly announced the introduction of a new universal family benefit, which would grant $€ 2,500$ to all new mothers. The subsidy would be paid for all children born from July 1, 2007 onwards. Three years later, during the economic crisis, the same prime minister suddenly announced on May 12, 2010 that the benefit would remain in place only until the end of 2010.

We combine publicly available birth-certificate microdata with restricted-access microdata on registered abortions. We find that the introduction of the policy led to a temporary increase in birth rates of $0.9 \%$ due to an immediate decrease in abortions, and to an additional, longer-term increase of $1.7 \%$ caused by a rise in conceptions. When the policy's cancellation was announced, a temporary increase in birth rates of $4.1 \%$ occurred in the period leading up to its actual elimination, driven by a temporary decrease in abortions. Meanwhile, the longer-term negative effect of the child benefit's cancellation on birth rates was $-5.5 \%$. 
In the heterogeneity analysis, we find that unmarried women reacted through fewer abortions in the early months after the introduction of the policy. Furthermore, the introduction effects on fertility are found only among couples where at least one partner is high-skilled. Meanwhile, the cancellation effects are driven by couples where both partners are low-skilled or out of the labor force. Additionally, we find that general economic conditions did not play a role during the introduction of the child benefit (in a booming economy), but were relevant after its cancellation (during an economic crisis). Indeed, fertility reacted twice as much to the benefit's cancellation in poorer provinces, and four times as much in provinces more affected by the crisis. Finally, we find suggestive evidence that the child benefit led both to a change in the timing of births (tempo effect) and to an increase in completed fertility (quantum effect).

\section{Institutional background}

On July 3, 2007, the Spanish prime minister announced in a national speech that a universal child benefit would be introduced. For every child born or adopted starting on July 3, 2007, families would receive a lump-sum payment of $€ 2,500$. This benefit was to be paid in addition to any other child support or assistance to which the family was already entitled. The proposal was approved shortly afterwards by the Spanish government on July 13, 2007, at which time it was declared that the parliament would pass the new law in an accelerated procedure in November of that year, with actual payments beginning in December 2007.

The policy announcement was widely covered in the main national news media. ${ }^{3}$ The government launched helplines, provided request forms, and began managing the latter in social security offices in mid-July 2007. The law was officially passed on November 15, 2007, and in its

${ }^{3}$ See for instance El País (2007a and 2007b) and La Vanguardia (2007). 
final form stipulated that all children born or adopted as of July 1, 2007 would be eligible for the universal child benefit of $€ 2,500$. Eligible parents included both Spanish and foreign nationals who had resided legally in Spain for at least two consecutive years prior to the birth or adoption. The benefit would be delivered in the form of a tax deduction, or directly in cash.

Three years later, on May 12, 2010, the same prime minister suddenly declared that the socalled "baby check" would only be granted until the end of the 2010 calendar year. Thus, families with births or adoptions starting from January 1,2011 would not receive the universal child benefit. The cancellation of the policy came unexpectedly, as in 2009 the prime minister had categorically denied any plans of its elimination. In fact, the government's intention to substantially cut expenditure due to the ongoing economic crisis became public just one week prior to the declaration of the child benefit's cancellation. The news was widely covered in the media, both in May 2010 upon its announcement and in December 2010 when the benefit ended. ${ }^{4}$

Benefit take-up appears to have been close to full. The "baby check" was widely publicized, and mothers were given request forms directly after giving birth in the hospital. We collected aggregate data on the number of tax returns requesting the universal child benefit in 2007-2010 from the Spanish tax authorities, as well as the number of claims made directly to the social security offices. These records show that the total number of claims was very close to the registered number of births and adoptions that took place in Spain during the relevant period. ${ }^{5}$

Throughout its existence, the universal child benefit had a nominal value of $€ 2,500$, which, at the time, constituted between $150 \%$ (when introduced) and 130\% (when cancelled) of average

\footnotetext{
${ }^{4}$ See for instance RTVE (2010) and El Mundo (2010).

${ }^{5}$ Depending on the source, between 1,610,000 and 1,960,000 child benefit claims were made, while approximately $1,770,000$ children were born or adopted.
} 
gross monthly earnings in Spain. ${ }^{6}$ In terms of the costs of raising children, it is estimated that this amount covers the first 5-6 months after childbirth. ${ }^{7}$

When the benefit was introduced and for its duration, women were entitled to 16 weeks of maternity leave with $100 \%$ wage replacement, and men to 2 weeks of paternity leave, also fully compensated. ${ }^{8}$ Women who returned to work after birth were also eligible for an annual tax benefit of $€ 1,200$ for up to 3 years. Public childcare was available, with priority given to low-income and single mother households, and there was no shortage of private childcare.

Meanwhile, abortion has been legal in Spain since 1985 where there is risk to the life or to the physical or mental health of the woman, as well as in cases of fetal deformations and rape. The vast majority of registered abortions claimed risk to the health of the mother, usually her mental well-being. Although the law gave no explicit limit in terms of weeks of gestation, more than $90 \%$ of abortions took place before 16 weeks of gestation. In 2010, a reform allowed abortions at the woman's request until 14 weeks of gestation (we return to this reform in Section 6.1).

\section{Expected effects and their timing}

The child benefit was a generous, one-time, lump-sum transfer, i.e., a positive income shock for families with newborn children in Spain. In the context of Becker's (1960) basic model of fertility, the benefit represents a reduction in the cost of raising children (the "price" of offspring), and is

\footnotetext{
${ }^{6}$ The real value of the benefit at the time of introduction was $250 \%, 190 \%$, and $130 \%$ of the $25^{\text {th }}$ percentile, median, and $75^{\text {th }}$ percentile of gross monthly earnings, respectively $(310 \%, 220 \%$, and $150 \%$ of female gross monthly earnings). Earnings data come from wage surveys conducted in 2006 and 2010 by the Spanish statistical office (INE).

${ }^{7}$ Our calculation is based on a report by Save the Children (2018), which estimates that the costs of raising children aged 0-3 years amounted to $€ 479$ and $€ 551$ per month in poorer and richer regions of Spain in 2018, respectively, which corresponds to $€ 418$ and $€ 481$ in 2007 prices.

${ }^{8}$ Paternity leave was extended from 3 days to 2 weeks in March 2007.
} 
predicted to increase fertility via both income and substitution effects. We thus expect that the benefit's introduction led to a higher birth rate, while its cancellation lowered fertility.

Beyond these general predictions, the expected effects of an income shock (on consumption as well as on fertility) will depend on whether the shock is transitory or permanent, anticipated or not, insurable or not, and large versus small (Meghir and Pistaferri 2011). They also depend on whether there are liquidity constraints or adjustment costs. As the Spanish child benefit was a transitory, unanticipated, and relatively large income shock, we consequently expect stronger effects on fertility among families facing more liquidity or credit constraints.

We also expect potentially asymmetric effects of the benefit's introduction and its cancellation. The standard life-cycle model of permanent income with perfect capital markets suggests that the marginal propensity to consume (MPC) is the same for positive and negative income shocks. However, Christelis et al. (2019) show that, in the presence of liquidity constraints, the MPC is higher for negative income shocks. They also provide empirical evidence that the consumption response is larger for negative shocks. In the case under study, we might therefore expect stronger effects of the benefit's cancellation compared to its introduction.

In what follows, we outline the timing of the expected fertility effects of the introduction and cancellation of the benefit. In doing so, we distinguish between the potential effects on conceptions and abortions. Figure 1 summarizes the timing of the announcement and implementation of the policy's introduction and its later cancellation, together with the timing of the expected effects on fertility, crucial for our identification strategy.

\subsection{Timing of the effects of the benefit's introduction}

As mentioned, the policy was announced in July 2007, and came into force immediately. Fertility may have reacted to the new policy through more new conceptions, as well as fewer abortions. 
(i) Abortions: The benefit announcement could have led to an immediate reduction in abortions.

Fewer abortions starting in July 2007 would, in turn, have led to more births starting in December 2007. ${ }^{9}$

(ii) Conceptions: An increase in conceptions starting in July 2007 would have led to a rise in births starting in April 2008, assuming that conception can take place within a few weeks after a couple starts trying to conceive, and the pregnancy lasts for approximately 39 weeks.

We thus expect that the introduction of the benefit increased birth rates starting from December 2007 (through fewer abortions), with an additional rise beginning in April 2008 (through new conceptions).

\subsection{Timing of the effects of the benefit's cancellation}

The cancellation was announced on May 12, 2010, and became effective as of January 1, 2011. Due to the staggered timing of the announcement (May 2010) and its implementation (January 2011), we can distinguish two potential effects on fertility: a transitory effect (May-December 2010), and the main effect (January 2011 onwards).

Main effect: We expect that the benefit's cancellation decreased fertility, both due to fewer conceptions and more abortions.

\footnotetext{
${ }^{9}$ Calculations are based on the following statistics: About 94\% of abortions in Spain in 2006 took place up to 16 weeks of gestation, while the average birth took place at 39 weeks. The average, median, and modal weeks of gestation at abortion were 9,8 , and 7 , respectively. The average and median birth took place at 39 weeks of gestation, whereas the mode was 40 weeks. These statistics are based on authors' calculations using microdata covering the universe of births and abortions in Spain in 2006.
} 
(i) Abortions: There may have been an increase in abortions among families with a due date in January 2011 or later. The bulk of this increase would have started in August $2010,{ }^{10}$ and these abortions would have resulted in a decrease in births starting in January 2011.

(ii) Conceptions: A decrease in new conceptions starting in May 2010 would have resulted in a decline in births beginning in February 2011.

In sum, we expect an increase in abortions starting in August 2010, and a negative effect on births from January 2011 on.

Transitory effect: In addition to the main effect, there may have been a transitory effect on fertility due to the different timing of the announced cancellation and its actual implementation.

(i) Abortions: The cancellation announcement may have led some pregnant women with a due date in 2010 to forego an abortion (and obtain the subsidy). Depending on the stage of the pregnancy, fewer abortions between May and July 2010 would have resulted in additional births just before the elimination of the child benefit (between October and December 2010).

(ii) Conceptions: Given that the window of time between the announcement of the cancellation and its implementation was 33 weeks, we do not expect couples to have reacted with additional conceptions immediately after the announcement, as childbirth from these pregnancies would not have occurred before the benefit's elimination.

In sum, we expect a transitory effect of the announced cancellation of the benefit on fertility, via a decrease in abortion rates between May and July 2010, leading to an increase in birth rates between October and December 2010.

\footnotetext{
${ }^{10}$ Since a woman in gestation week 16 (or less) in early August 2010 would give birth in January 2011 (or later).
} 
Birth timing effect: Beyond its effects on conceptions and abortions, the announced cancellation may also have led to an effect on birth timing: some families with a due date in early January 2011 may have scheduled an early elective delivery in late December 2010. Borra, González, and Sevilla (2019) estimate that there were around 2,000 such early births. We take this behavior into account in our estimation, as it could bias our findings relative to the cancellation effects on fertility.

\section{Data sources}

We use administrative microdata on births and abortions in Spain between 2000 and 2017.

\subsection{Birth data}

Data on births come from the Spanish administrative registry of births, collected and made publicly available by the Spanish statistical office (INE 2019). These microdata encompass the universe of all 7,932,077 births that took place in Spain in the years 2000 to 2017. The data set includes information on month and year of birth of each child, and socio-demographic characteristics of the

parents. We created a panel of monthly birth rates at the province level. Specifically, we calculated the number of births per day in each calendar month, restricting to women aged 15 to 44 resident in one of the 50 Spanish provinces, and dividing it by the number of women aged 15-44 residing in that province and calendar month. Data on the number of women aged 15-44 also come from the INE, which reports population at the province level in January and July of each year. We linearly interpolate population sizes for the remaining months.

Rather than number of children born, we count the number of births, such that multiple births are counted only once. We include both live and still births $(0.3 \%$ of births in our data resulted in death). We exclude women aged 12-15 and 50-55 (0.05\% of births). We also exclude 45-49-yearold women ( $0.27 \%$ of births). The share of women aged $45-49$ over women aged 15-49 increased from $12 \%$ to $18 \%$ between 2000 and 2017 . Thus, including this group (with very few births but an 
increasing relative size) would distort the birth rate. We exclude two province-cities that belong to Spain but are located in North Africa (Ceuta and Melilla, with $0.25 \%$ and $0.29 \%$ of births, respectively), and mothers who are not residents in Spain ( $0.32 \%$ of births). We calculate the number of births and birth rates per day in a calendar month to enable comparability across months with different numbers of days.

We have 216 monthly observations per province for years 2000-2017, and 10,800 observations overall. Figure A1 shows the daily number of births by calendar month in Spain between 2000 and 2017, while Figure 2 depicts the corresponding birth rate. The vertical lines mark the period during which the universal child benefit was in effect. There were 474,461 births to women aged 15 to 44 in Spain in 2006 (the year before the benefit's introduction), or about 5 annual births per 100 women. ${ }^{11}$

\subsection{Abortion data}

We use microdata encompassing the universe of all 1,738,188 abortions registered in Spain in the years 2000 to 2017 from the Ministry of Health (MSCBS 2019). The data set includes information on the exact date of the procedure, reason for the abortion, gestation weeks, and basic sociodemographic characteristics of the woman.

We use a similar approach as that applied to the birth data, creating a panel of weekly abortion rates at the province level. These are expressed per day in each week, and include women aged 15 to 44 resident in one of the 50 Spanish provinces. We again exclude women aged below 15 and above 44 ( $0.88 \%$ of abortions), and abortions performed on residents in the two provincecities located in North Africa ( $0.11 \%$ of abortions) and on non-residents ( $2.14 \%$ of abortions).

${ }^{11}$ Total population in this age range in 2006 was almost 9.75 million women. 
Figures A1 and 2 show the daily number of abortions and the corresponding abortion rate by month in Spain between 2000 and 2017, respectively. The vertical lines mark the announcement of the introduction and that of the cancellation of the child benefit. There were 100,714 abortions to women aged 15 to 44 registered in Spain in 2006, which amounts to about 1 annual abortion per 100 women. Contrasting the number of abortions with the number of births in the same year (474,461 births) suggests that about 18 out of every 100 pregnancies were aborted.

\section{Methodology}

Women may have reacted to the introduction and cancellation of the child benefit with changes in abortions and new conceptions, both of which would have resulted in a shift in the number of births. Our identification of birth effects relies on capturing deviations from a smooth time trend at specific points in time (identified in Section 3), after controlling for economic conditions. Births react with a varying time delay, due to the time necessary to conceive and due to pregnancy length. Meanwhile, abortions can, in principle, react immediately. We accordingly estimate different models for births and abortions, as follows.

\subsection{Effects on births}

In order to analyze the effects of the benefit on realized fertility, we construct a panel with monthly observations for the 50 Spanish provinces over the period 2000-2017 (i.e., from 7 years before the policy's introduction to 7 years after its cancellation). We estimate the following equation:

$$
Y_{p t}=\alpha+\sum_{j} \gamma_{p j} t_{p}^{j}+\sum_{k=1}^{4} \beta_{k} T_{k}+\rho X_{p, t-9}+\delta_{p}+\theta_{m}+\varepsilon_{p t}
$$


where the dependent variable $\boldsymbol{Y}$ is either the natural $\log$ of the number of births per day in province $\boldsymbol{p}$ in month $\boldsymbol{t},{ }^{12}$ or the corresponding birth rate, for women aged 15 to 44 . We estimate fixed effects regressions in which fertility is allowed to follow a polynomial $(j)$ time trend $(t)$, and this time trend can vary by province $(\boldsymbol{p})$. In order to estimate the effects of the universal child benefit $(\boldsymbol{\beta})$, we allow the time trend to "jump" in four time periods $(\boldsymbol{T})$, defined according to the expected timing of the effects (see Section 3). There are thus five periods:

$$
\begin{array}{lll}
\mathrm{k}=0: & 01 / 2000-11 / 2007 & \text { Pre-child-benefit period } \\
\mathrm{k}=1: \quad 12 / 2007-03 / 2008 & \begin{array}{l}
\text { Transition into child benefit (potential effect of child benefit on } \\
\text { births due to fewer abortions) }
\end{array} \\
\mathrm{k}=2: \quad 04 / 2008-09 / 2010 & \begin{array}{l}
\text { Child benefit period (potential effect of child benefit on births due } \\
\text { to fewer abortions and more conceptions) }
\end{array} \\
\mathrm{k}=3: \quad 10 / 2010-12 / 2010 & \begin{array}{l}
\text { Transition out of child benefit (potential effect of the announced } \\
\text { benefit's cancellation on births due to a transitory decrease in }
\end{array} \\
& \text { abortions) } \\
\mathrm{k}=4: \quad 01 / 2011-12 / 2017 & \begin{array}{l}
\text { Post-child-benefit period (potential effect of the benefit's } \\
\text { cancellation on births due to more abortions and fewer } \\
\text { conceptions) }
\end{array}
\end{array}
$$

We thus include four binary variables $\boldsymbol{T}_{\boldsymbol{k}}$ that take a value of 1 in periods $\mathrm{k}=\{1,2,3,4\}$.

We include lagged male employment and unemployment rates to control for economic conditions $(\boldsymbol{X})$, calendar month of birth fixed effects to control for seasonality $\left(\boldsymbol{\theta}_{\boldsymbol{m}}\right)$, and province fixed effects to control for time-invariant characteristics of each province $\left(\boldsymbol{\delta}_{\boldsymbol{p}}\right)$. The

12 If there are no births (or abortions) in a certain province and month, we replace $\log (0)$ with $\log (0.01)$. The minimum non-zero daily number of births (or abortions) is $0.0323(=1$ event/31 days). 
(un)employment rates are available quarterly at the province level, and we consider a 3-quarter lag, reflecting economic conditions at the time of conception. Inclusion of (un)employment rates is crucial, given that the economic crisis in Spain started after the universal child benefit was introduced. Standard errors are clustered at the province level.

Our identifying assumption is that other time-varying factors affecting birth rates did not change discontinuously at the national level at the same time as the benefit's introduction and cancellation. We control for labor market conditions directly, and all other time-varying factors are captured by our province-specific smooth trends.

Conceptually, the introduction of the child benefit may have led to a jump in birth rates (i.e., a change in level), but also to a shift in the trend (i.e., a steeper positive slope), or both. Since the time periods that we are looking at are rather brief, there is not enough variation to separately estimate changes in slopes and levels, while also controlling for seasonality in birth rates. We therefore simplify the model, which estimates (1) smooth, long-term regional trends in birth rates and (2) national-level shifts in the overall fertility level during the different time periods. It thus does not tease out the source of these shifts (e.g., a change in the slope, a jump in birth rates, or both).

\subsection{Effects on abortions}

Given that abortions can react immediately, we employ a regression discontinuity design (RDD) to estimate the effects of the benefit's introduction and cancellation. The running variable is the week in which an abortion takes place. In order to account for seasonality, we always include the previous year as a control, so that the approach combines an RDD with difference-in-differences (DiD). 
We restrict the sample to the immediate neighborhood of the announcement ("cut-off"), and to the same time period in the previous year, estimating the following equation:

$$
\begin{gathered}
Y_{p t}=\alpha+\beta \text { Post } * \text { ReformYear }+\gamma \text { ReformYear }+\theta_{t}+\delta_{p}+\varepsilon_{p t} \\
\forall t \in\left(c_{\text {ControlYear,ReformYear }}-8, c_{\text {ControlYear,ReformYear }}+7\right), \\
\text { Post } \equiv 1(t \geq c),
\end{gathered}
$$

where the dependent variable $\boldsymbol{Y}$ is either the natural $\log$ of the number of abortions per day in province $\boldsymbol{p}$ and week $\boldsymbol{t}$, or the corresponding abortion rate, for women aged 15 to 44 . The forcing variable is the week $\boldsymbol{t}$. The cut-off $\boldsymbol{c}$ is the week that starts one day after the announcement, i.e., July 4, 2007 for its introduction, and May 13, 2010 for the cancellation regressions.

The interaction Post*Reform Year is a binary variable that takes a value of 1 for the weeks post-July 3, 2007 and post-May 12, 2010 in the introduction and cancellation regressions, respectively, and 0 otherwise. The key parameter of interest is $\boldsymbol{\beta}$, which identifies the (immediate) change in abortions once the introduction or cancellation of the benefit is announced, net of seasonality effects.

We control for calendar year (Reform Year), week $\left(\boldsymbol{\theta}_{\boldsymbol{t}}\right)$, and province $\left(\boldsymbol{\delta}_{\boldsymbol{p}}\right)$ fixed effects. ${ }^{13}$ Standard errors are clustered at the province level. The main sample includes observations within a window of 8 weeks before and after the cut-off.

\section{Results}

\subsection{Main results}

We first present the results for birth rates, and then explore the role of abortions.

\footnotetext{
${ }^{13}$ Note that the post-announcement-weeks dummy (Post) is not included separately because it is collinear with week fixed effects.
} 


\subsubsection{Effects on births}

Our empirical results are consistent with the child benefit leading to a significant increase in birth rates, which reversed after its cancellation. We start by providing descriptive graphical evidence. Figure 3 depicts the variable of interest (the daily birth rate per 100,000 women of reproductive age) for each calendar month separately, where we observe a positive time trend between 2000 and 2008. Fertility peaks in 2008, and a negative trend follows.

This shift coincides with the onset of the economic crisis in Spain in 2008, which saw an increase in male unemployment rate from 6\% to 27\% between 2007 and 2013 (see Figure A2). The aforementioned figure highlights the importance of controlling for local labor market conditions, given that 2008-2010 was a period of rising joblessness. Note, however, that employment and unemployment rates evolved smoothly around the benefit's introduction and cancellation cut-offs. ${ }^{14}$

In line with the expected effects of the child benefit, there is an unusually high peak in the birth rate in April 2008, followed by further peaks in the following months (May-September 2008). This pattern aligns with the increase in fertility that would result from new conceptions shortly after the child benefit was announced in July 2007. Figure 3 also suggests that the positive effect of the benefit on fertility was not persistent, since the peak lasted for only about six months.

Furthermore, Figure 3 shows a clear disproportionate increase in births in October-December 2010 (and partly as soon as September 2010), which aligns with the expected temporary decrease in abortions after the cancellation announcement in May 2010. Finally, we observe an extraordinarily high birth rate in December 2010 (the peak is much larger than in October-

${ }^{14}$ Crucially, the national unemployment rate started to rise four quarters after the benefit's introduction and the expected increase in births. It then continued to rise for two full years after the benefit's cancellation. These clear differences in timing allow us to separate the two effects. 
November 2010), followed by a dip in January 2011, thus providing graphical evidence of a birth timing effect. Specifically, some parents likely scheduled early elective deliveries in December 2010 as a reaction to the approaching cancellation of the child benefit (Borra, González, and Sevilla 2019).

Figure 4 zooms in on the birth rate around the time when the child benefit was in place. The dashed lines mark points in time when the effects of the introduction or cancellation of the policy are expected to affect the birth rate. As seen in Figure 3, there is a clear increase in births in April 2008 that lasts for a few months, and then another increase in October-December 2010. ${ }^{15}$

Overall, the graphical evidence is consistent with the expected effects of the child benefit on fertility. ${ }^{16}$ In order to quantify these effects, Table 1 presents our main regression results (equation 1). The effects of the child benefit on fertility are estimated through four coefficients measuring shifts in birth levels coinciding with the four periods of interest. Coefficients are always reported as the estimated change relative to the previous period.

Column 1 shows the results from the specification with the number of births in logs as the dependent variable and a national-level fertility trend. ${ }^{17}$ In column 2 , we allow for different fertility

15 There would seem to be a large increase as early as September 2010. Note, however, that September systematically has the highest birth rate (see Figure 3). In fact, there occurred only a small disproportionate increase in September 2010, which may be an effect of fewer (late) abortions following the announcement in May 2010.

16 The child benefit also covered adoptions. Figure A3 shows annual data on the number of adoption requests (we focus on requests rather than actual adoptions as adoptions can be a lengthy process). National adoption requests increased substantially in 2007 and then peaked in 2008 (left panel). They later decreased in number, though remained well above the pre-policy level. This figure suggests that couples reacted to the benefit with an increased interest in national adoptions. We do not observe a similar pattern for international adoption requests (right panel). If anything, the number of such requests declines in the period 2006-2014.

${ }^{17}$ In every regression, we allow for the time trend to be linear, quadratic, and cubic, and then we choose the most flexible time trend that is statistically significant. In column 1, the most flexible significant time trend is quadratic. 
trends across provinces. We also conduct a donut estimation (column 3), where we exclude births in 12/2010 and 01/2011, due to the documented shift in birth timing (Borra, González, and Sevilla 2019). A comparison of the results in columns 2 and 3 reveals that ignoring the birth timing effect leads to substantial bias in our estimates of the cancellation effect. The donut approach is therefore our preferred specification.

We find that births increased by 3.5\% starting in December 2007 (column 3), which we interpret as the result of fewer abortions after the policy was announced in July 2007. Births increased a further 2.8\% beginning in April 2008, likely the effect of new conceptions. Just before the cancellation of the policy, in October-December 2010, we find a substantial rise in births of 4.7\%, in line with fewer abortions immediately after the cancellation announcement in May 2010. Finally, after the actual cancellation of the benefit, we observe a 5.7\% decrease in births, which could be the result of both more abortions (starting in August 2010) and fewer conceptions (starting in May 2010).

Column 4 adds a control for the number of women of reproductive age, since the female population in Spain changed nonlinearly over the period 2000-2017 (Figure A4). Given that some of the coefficients become smaller, we also estimate the effects on birth rates (column 5). We find that the daily birth rate (per 100,000 women) increased by 0.12 during the transition into the child benefit, by 0.22 during the child benefit, and by 0.53 during the transition out of the child benefit. After the benefit's cancellation, the birth rate fell by 0.70 births per 100,000 women. ${ }^{18}$ For context, the average daily birth rate in Spain in the twelve months prior to July 2007 and May 2010 was 12.6 and 12.7 births per 100,000 women, respectively.

\footnotetext{
18 The results are robust to using weights (population of women of reproductive age 15-44 in each calendar month in each province).
} 
Overall, we estimate that benefit's introduction increased birth rates by $0.33(\sim 0.12+0.22)$, while its cancellation resulted in a decrease of 0.70 births per 100,000 women, a magnitude almost twice as large. These results are consistent with the prediction that negative income shocks have stronger effects than do positive ones (Section 3).

As a robustness test, we run a set of "placebo" regressions where we estimate changes in the birth rate in "fake" policy years. We explore 20 different combinations of "fake" policy dates, estimating specifications where the "introduction" year is 2003, 2004, 2005, 2006, or 2008 (instead of 2007), and the "cancellation" year is 2009, 2011, 2012, or 2013 (instead of 2010). ${ }^{19}$ The findings are presented in Table A1. The first row shows the results of our main specification with the true introduction and cancellation dates. The four coefficients of interest are statistically significant and show the predicted signs. This is not the case for any of the following 20 variations of different "fake" policy years. The "true" combination of reform dates is the only one where the estimated coefficients are in line with the expected effects.

\subsubsection{Effects on abortions}

At this point, we have observed that the shifts in births are consistent with (predicted) preceding changes in abortions. In order to directly document this link, we estimate the effects of the introduction (July 2007) and cancellation (May 2010) announcements on the number of abortions and abortion rates. In our preferred specification, we include only abortions unrelated to fetal deformations ( $97 \%$ of all abortions), since those due to fetal health concerns are less likely to react to financial incentives. Since abortions can react immediately, we estimate the effects on abortions in an RD-DiD framework.

\footnotetext{
${ }^{19}$ The calendar month of the introduction and cancellation in "fake" policy years is kept the same
} as in true policy years. 
Figure 5 illustrates the results graphically. Panel A shows weekly abortion rates before and after July 4 in the benefit's introduction year 2007 (right) and in the previous year 2006 (left), including linear trends before and after the threshold. We see a much more pronounced decrease in weekly abortion rates in July 2007 (right) compared to the control year 2006 (left).

Table 2 (column 1) shows the regression results for the RD-DiD specification in equation (2), where, instead of linear trends, we include controls for seasonality (week fixed effects). The coefficient in panel B documents a significant decrease in the abortion rate after July 4, 2007 of about 0.15 daily abortions per 100,000 women.

As for the cancellation of the benefit in May 2010, the RDD graph in panel B of Figure 5 shows no clear discontinuity on May 13, 2010. That said, there are unusually few abortions seven to nine weeks after the cancellation announcement (in late June), not visible in the control year 2009. When we use an 8-week window, column 2 in Table 2 does suggest that there occurred a significant decrease in abortions after May 13, 2010 relative to the same weeks in 2009. Here again, the magnitude is about 0.15 daily abortions per 100,000 women.

In addition to an immediate, transitory decline in abortions in May 2010, we also expect an increase in abortions starting in August 2010, as explained in Section 3. While, in this case, we do not have a sharp RDD, it is still possible to estimate whether there was a discrete change in the number of abortions starting in August 2010 (Table 2, column 3). ${ }^{20}$ Abortions did, in fact, increase beginning this month, corresponding to pregnancies with due dates in early 2011 , which would not have been eligible for the child benefit. ${ }^{21}$ The magnitude of the increase, about 0.37 daily

20 The sample includes the periods of March 14-May 8 and August 1-September 25 of 2009 and 2010. Abortions in May 13-July 31 are excluded since they were affected by the transitory effect of the opposite sign. Their inclusion makes the estimated effects larger (as expected).

${ }^{21}$ Spanish abortion law changed on July 5, 2010. As of that date, abortion became permissible at the woman's request in the first 14 weeks of gestation. This reform could have increased the 
abortions per 100,000 women (panel B), is more than twice the size of the decrease after the benefit's introduction (column 1). ${ }^{22}$

The estimated effects are robust to including abortions due to fetal deformations (Table A4, columns 1-3). At the same time, we find no effects for the subsample of fetal deformations, which are less likely to react to financial incentives (Table A4, columns 4-6).

Overall, the estimated effects of the child benefit on abortion rates map into the estimated effects on subsequent birth rates. We find a decrease in abortion rates in July 2007 , followed by an increase in birth rates in December 2007. A decrease in the abortion rate in May 2010 is then followed by an increase in the birth rate later that year, in October-December 2010. Finally, an increase in the abortion rate in August 2010 is followed by a decrease in the birth rate in January 2011.

\subsection{Heterogeneous effects}

Economic theory suggests that the effects of the child benefit on fertility should be stronger for women and families with fewer economic resources. In this section, we test this hypothesis with the available data, for both the benefit's introduction and cancellation. Since we do not observe

incidence of abortions. In Table A2, we test directly for its effect with an RD-DiD specification with weekly number of abortions (the week starting on July 5, 2010 is the cut-off). We find no significant increase in abortions in regressions with a broader bandwidth (4 weeks). If anything, we observe a significant decrease in abortions in regressions with narrower bandwidths (1-3 weeks). The estimated increase starting in August 2010 (Table 2) thus seems unrelated to contemporaneous changes in legislation.

${ }^{22}$ We also estimate an alternative RD-DiD specification where the dependent variable is the number of abortions with a due date in a specific week (instead of abortions taking place in a specific week). The cut-off is January 1, 2011 (see Table A3). When we use a 16-week window, we find a significant increase in abortions for pregnancies due in January 2011, relative to December 2010. The coefficients in this specification are not significantly different from those in Table 2. 
household income directly, we use a series of proxies, running fully interacted models to test for heterogeneous effects across groups.

As proxies for income at the individual level, we use maternal age and marital status, as well as mothers' and fathers' occupation. ${ }^{23}$ Figure A5 shows the number of births in 2000-2017 for the different subgroups. ${ }^{24} \mathrm{We}$ also employ the per capita income of the province where mothers reside so as to divide regions into low- and high-income. ${ }^{25}$ Finally, since some regions were more strongly affected than others by the recession that began in 2008 , we explore potential heterogeneous effects of the benefit's cancellation in those areas more heavily hit by the crisis. To identify more and less affected regions, we use the increase in the male unemployment rate at the province level. ${ }^{26}$

The main results for the heterogeneity analysis are presented in Tables 3 to 5 . Table 3 shows the results for the heterogeneity effects on births by individual characteristics, while Table 4

${ }^{23}$ Mothers are divided into a "younger" (15-32 years; $57 \%$ of the sample) and an "older" age group (33-44 years; 43\%) based on median maternal age in 2000-2017. Parents are classified as having a high-skilled occupation if they are employed (at the time of birth) as administrators, technicians, or scientific workers (37\% of mothers and $30 \%$ of fathers in our sample). The remaining parents, referred to as "not-high-skilled," either belong to other occupational groups (25\% of mothers and $53 \%$ of fathers), or are not working (38\% of mothers and $17 \%$ of fathers).

${ }^{24}$ Note that Figure A5 and all the heterogeneity analyses focus on the number of births/abortions rather than the preferred birth/abortion rates. The latter cannot be calculated, as we do not observe the denominator, i.e., the number of women living in Spain who belong to each sub-group.

${ }^{25}$ We use data on GDP per capita in each province in 2007 and 2010 to create a province-level indicator of income level. The provinces are first ranked according to their GDP p.c. in each year. We then create a binary variable that takes a value of 1 for the 25 provinces that were relatively poorer in 2007, and 0 otherwise. We assign these values to each province for the months of January 2000-April 2010. For the months of May 2010-December 2017, the binary variable takes a value of 1 for the 25 provinces that were relatively poorer in 2010 . Only two provinces change their income status between 2007 and 2010.

${ }^{26}$ We define our crisis measure as the absolute increase in the male unemployment rate in a province between the time when it was at its lowest (third quarter of 2006; 6.0\%) and highest (first quarter of 2013; 26.7\%) in Spain nationwide. We then rank the 50 provinces and create a binary variable that indicates a more intense exposure to the crisis. This variable takes a value of 1 for the 25 provinces that experienced a larger increase in the male unemployment rate, and 0 for the rest. 
displays the corresponding results for abortions. Table 5 depicts the findings regarding the effects on births by income level and by unemployment rates in the region.

\subsubsection{Effects of the benefit's introduction}

We first discuss the results for the effects of the benefit's introduction. The upper panel of Table 3 presents the coefficients for the main effects of the benefit's introduction and cancellation, while the lower panel shows the coefficients on the interaction with the proxies for the lower-income subgroups. The interaction coefficients test the hypothesis that the effects were different among poorer households.

The interaction coefficients for the "transition into the child benefit" (second panel of Table 3) show that the increase in births following the benefit's introduction was driven by younger and unmarried women (columns 1 and 2). These coefficients arguably capture effects driven by reductions in abortions. We show the corresponding abortion results in Table 4 (columns 1 and 2). Though we do not find statistically different effects on abortions for younger or single women, abortions are much more common among these two groups (see averages at the bottom of Table 4). This implies that the same proportional reduction in abortions would lead to a larger decrease in abortions in absolute terms (and hence, a larger increase in births) among younger and unmarried women.

The third column in Table 3 shows the effects for parent(s) employed in high-skilled occupations versus the others. ${ }^{27}$ We find that the effect of the benefit's introduction on births is actually driven by the high-skilled group (both the transition and the main effect), since the

\footnotetext{
27 As we do not observe parental education before 2007, we use occupation type as a proxy of
} income. 
interaction coefficients for the low-skilled parent(s) $)^{28}$ are negative and significant (column 3 , second panel). Table A5 shows that this is also the case when we look separately at the occupation of mothers and fathers.

As this unexpected result is not consistent with our main prediction, we further explore by analyzing the effect of the child benefit on partnership formation by skill level. To this end, we collected administrative data on the annual number of marriages in Spain between 2000 and 2017, and ran similar regressions for the log number of marriages (note that there is no reason to expect "transition effects" in the case of marriages). The results are reported in Table A6. We find an increase in marriages with high-skilled partners following the benefit's introduction, and a reduction in the number of partnerships with low-skilled spouses. Thus, the marriage effects mirror those for births. We could not find any factor other than the benefit that could explain the rise in both marriages and births to high-skilled couples after its introduction..$^{29}$

Table 5 shows the results by per capita income of the province (columns 1 and 2). We find no differential effects of the benefit's introduction between richer and poorer provinces.

\subsubsection{Effects of benefit's cancellation}

We now turn to the effects of the cancellation of the benefit. We begin by analyzing heterogeneity in the transitory increase in births after the cancellation announcement, driven by a reduction in abortions. The second panel of Table 3 shows that this effect was, if anything, driven by older

${ }^{28}$ Note that this category includes both low-skilled individuals and those out of the labor force, but we will refer to them as "low-skilled" for presentational purposes.

${ }^{29}$ Milligan (2005) similarly finds that higher-income parents reacted more strongly to increases in child benefits in Canada. 
women (column 1), while we find no significant differences by marital status or occupation (columns 2 and 3).

Table 4 (middle panel) depicts the corresponding abortion effects. While the interaction effects are not significant, columns 2 and 3 do suggest that the decrease in abortions was larger among unmarried and less educated women. ${ }^{30}$

Regarding regional income effects, we find that the increase in births following the cancellation announcement was stronger in lower-income provinces (Table 5, second panel, columns 1 and 2), as well as in those hit harder by the recession (columns 3 and 4).

Finally, we focus on the last set of coefficients, corresponding to the negative fertility effects of the benefit's cancellation, beyond the transitory announcement effects. Table 3 (last row of the second panel) indicates that the reduction in fertility was considerably stronger for younger women (column 1), as well as for low-skilled couples (column 3). Table 4 (third panel) suggests that part of these effects on births may have been driven by an increase in abortions, since we find (insignificant) positive interaction coefficients for younger and low-educated women.

A consideration of regional economic conditions in Table 5 (second panel, columns 3 and 4) shows that the benefit's cancellation effects were considerably stronger in poorer provinces and those more affected by the rise in unemployment. Specifically, while the reduction in birth rates was -0.30 in provinces less affected by the recession (column 4 , first panel), regions that struggled (second panel) experienced a much more pronounced decrease (by an additional -0.81, i.e., four times larger).

${ }^{30}$ In the abortion data, we do not observe woman's occupation so we use her education as an income proxy. 
Our heterogeneity analysis thus reveals that the effect of the benefit's cancellation was significantly greater among younger and low-skilled parents, and in those areas that were poorer or more affected by the 2008 crisis (after controlling for the direct effects of the unemployment rate). This finding is consistent with the prediction that the benefit would have more of an effect on lower-income families. Moreover, the fact that poorer provinces did not react differentially to the benefit's introduction is consistent with the expectation that negative income shocks lead to stronger reactions than do positive shocks.

\subsection{Quantum versus tempo effects}

Thus far, we have provided evidence on the overall effect of the child benefit on fertility, and on the extent to which some subgroups reacted disproportionately. Another important question is whether the observed effects can be interpreted as actual increases in fertility (quantum effect), or if they merely reflect changes in the timing of otherwise unchanged fertility (tempo effect). In other words, did the documented increases in birth rates lead to a rise in completed fertility (for some women), or was the effect only temporary? Policy makers diverted substantial economic resources to finance the universal child benefit - a strategy that explicitly aimed to raise the fertility rate (quantum effect). Yet, whether this intervention was truly cost-effective depends on whether families ultimately had more children overall.

Given the short duration of the benefit (3.5 years), together with the onset of the economic crisis in this same period, it is challenging to clearly identify whether the overall number of children increased as a consequence of the benefit. Nevertheless, we present several pieces of evidence suggesting the presence of a quantum effect.

First, we estimate the effect of the benefit on births by parity. Columns 1 and 2 in Table 6 reveal that the positive fertility effect during the transition into the child benefit is driven only by 
higher-parity births. All subsequent effects are then found among both first and higher-parity births (albeit the magnitudes of the cancellation effects are substantially larger among higher-parity births). Importantly, all higher parity births are affected (Table 6, columns 3-5). Table A7 shows the estimated effects on abortions by parity. We also find effects for both women without children and for higher parities (although none of the coefficients are significant for parities higher than 2).

Overall, we find more births during the child benefit period at all parities. If the effect was exclusively of a tempo nature (i.e., stemming from having the same number of children, only earlier), we would not necessarily expect to see any increase among parities greater than 2 , as these are relatively rare ( $91 \%$ of births in 2006 were the mother's $1^{\text {st }}$ or $2^{\text {nd }}$ child).

Second, it is useful to explore the effects of the benefit on birth rates among women of different ages (Table 7). The positive effects of the policy's introduction were not restricted to younger women, which might occur where there is a pure tempo effect. For instance, the birth rate among women aged 35-39 increased substantially during the child benefit period (see column 5 in Table 7). Importantly, this positive fertility effect appears among women aged 35-39 at all parities (column 5 in panels A-D, Table A8). More first births among these "older" women (panel A) likely represent "additional" births, as the median age was 30 and 33 for first and higher-parity births in 2006, respectively. Moreover, the fact that all higher parities among these "older" women are positively affected (panels $\mathrm{C}$ and $\mathrm{D}$ ) also hints at additional births (i.e., a quantum effect).

That said, we also find evidence of a tempo effect. Birth rates among young women (aged 2024 and 25-29) increased (Table 7), and this happened across all parities (columns 2 and 3 in panels A-D, Table A8). In addition, the birth interval among women aged 20-24 who had a second child 
became significantly shorter (by 2 months) during the child benefit period (Table A9). ${ }^{31}$ Yet, it is also possible that these young women would have had additional children later on, if the policy had been in place for longer. In other words, such evidence of a tempo effect could instead represent the onset of a quantum effect, which would have been revealed only in the "medium run." 32

Finally, the short positive transitory effect on fertility just before the policy's cancellation led to additional births, demonstrated by the increase in second births among virtually all maternal age groups (panel C, Table A8). Furthermore, we observe a rise in less common parities $3+$ (women aged 30-34; column 4 in panel D, Table A8), in first births among "older" women (women aged 35-39; column 5 in panel A, Table A8), and in the general birth rate among "older" women (aged 35-44, Table 7). These additional births would seemingly not have occurred otherwise (quantum effect). Note, however, that this positive transitory effect was not explicitly intended by policy makers.

In sum, we cannot distinguish clearly whether the additional births among younger women were exclusively a tempo effect (i.e., young women had children earlier) or whether (some of) these births would have led to higher overall fertility, had the policy remained in place for longer (i.e., young women who decided to have more children as a reaction to the policy might have

\footnotetext{
${ }^{31}$ The only other statistically significant effect in Table A9 is an increase in birth interval among women of prime fertility age (25-29 and 30-34) during the child benefit. This is consistent with a quantum effect (i.e., women who had finalized their fertility with only one child, but who then decided to have another child, after a longer break).

32 Interpreting increasing birth rates among young women is generally not straightforward, particularly if observed only over a short period of time. For instance, more births of parity $3+$ among young women aged 20-24 (column 2 in panel D, Table A8) hint at a quantum effect, since parities higher than 2 are uncommon (9\% of births in 2006). On the other hand, these additional higher-parity births to young mothers could just as well reflect a tempo effect, if the increase took place exclusively among the population of women who would have had more than 2 children independently of the child benefit.
} 
started their reproductive life earlier and/or might have chosen shorter birth spacing). However, in looking at the evidence after just 3.5 years of the policy, we can say that the additional births documented seem to be the combined result of a tempo effect (among younger women) and a quantum effect (among older women). The potential onset of a quantum effect in the medium run among younger women cannot be identified due to the short duration of the policy.

\section{Discussion}

Our identification strategy relies on estimating changes in abortion and birth rates at specific points in time, following the timing of the introduction and then the cancellation of a child benefit. Two limitations are worth discussing. First, while abortions and intentions to conceive can react immediately to policy announcements, births respond with some delay, which varies across couples. This makes identification more challenging. Second, since we exploit before-after variation, it is important to consider other policy changes that may have taken place during the same time period.

Regarding the first issue, conception is in general not immediate, and the time necessary to conceive a child differs across couples. Moreover, not all conceptions result in a birth, as women can experience a miscarriage or opt for an abortion. Pregnancy length also varies naturally. ${ }^{33}$

We ideally would have liked to measure intentions to conceive, which can react immediately after policy announcements. We provide suggestive evidence that they did indeed react. We collected monthly data from Google trends on searches of words related to birth control in Spain over the period 2004-2013 (contraceptives, pill, and birth control pills). We run a simple regression where we include a linear trend, calendar month fixed effects, and two dummy variables of interest:

\footnotetext{
${ }^{33}$ In $2000-2017$, the $10^{\text {th }}, 50^{\text {th }}$, and $90^{\text {th }}$ percentiles of the distribution of weeks of gestation were 37,39 , and 41 .
} 
"post-July-2007" which takes a value of 1 from July 2007 on, and "post-May-2010" which takes a value of 1 from May 2010 on. As before, the coefficients are reported as a shift in levels compared to the previous period (Table A10). Daily searches decreased by 18-39\% starting in July 2007 (depending on the word and population). Conversely, searches increased starting in May 2010 by $22-28 \%$. This pattern suggests that couples' intentions to conceive rose with the announcement of the benefit, and then declined following the announcement of its cancellation.

Regarding the second issue, we attribute the documented changes in abortion and birth rates over time to the child benefit. Though the evidence is compelling, it is possible that other contemporaneous changes may have partly driven the observed fertility shifts. While we control for a smooth time trend as well as employment and unemployment rates, other relevant policy changes that occurred during the period of interest should also be considered.

One such reform was the introduction of a two-week paternity leave in March 2007. If the new policy led to an increase in conceptions, this could have contributed to more births starting in January 2008. Slightly earlier, in December 2007, we do indeed observe an increase in births, though we attribute this to fewer abortions after the introduction of the child benefit. In support of this interpretation, we show that there occurred a discrete decrease in abortions in July 2007. Additionally, Farré and González (2019) find that the introduction of paternity leave in Spain may, in fact, have lowered subsequent fertility.

Along with the announcement of the benefit's cancellation, several other public budget cuts were also declared in May 2010 due to the ongoing economic crisis. Some of these became effective as of January 2011. While they may have led to a decrease in birth rates starting from January 2011, it is harder to link them to the transitory increase in birth rates in October-December 
2010. In addition, the evidence we provide for abortion rates is well identified within an RD-DiD framework.

Furthermore, the abortion law in Spain changed in July 2010. We test directly for potential effects of this change on abortion rates (see Section 6.1.2) but find no evidence that the reform had an impact on the number of abortions.

Finally, having documented positive effects of the child benefit on birth rates, it is worth quantifying just how many additional births were induced by the policy, as well as comparing our findings to those in the previous literature.

First, we estimate the effects of the benefit on the absolute number of births in the different periods (column 6 in Table 1), and multiply the coefficients by the number of months in each period. ${ }^{34}$ According to this back-of-the-envelope calculation, the policy brought about an additional 70,000 births, or "2 extra months of births" over a 37-month period. As discussed above, some of these births reflect a mere timing (tempo) effect, while others were additional births (quantum effect).

Second, we can compare the magnitude of our estimated effects with previous findings in the literature. Milligan (2005) shows that an increase of $C \$ 1,000$ in first-year benefits increased fertility by $16.9 \%$ in Canada, while this same increase of $\mathrm{C} \$ 1,000$ over the first 5 years of a child's life increased fertility by $2.6 \%$. We find that a one-time benefit (granted in the first year) of $€ 2,500$ led to a $3 \%$ increase in birth rates in Spain, while its cancellation reduced fertility by $6 \%$.

${ }^{34}$ As the estimated effects are cumulative throughout the subsequent periods, and since we measure the dependent variable as births per day per province, the final calculation is: $\{[0.67 * 4$ months $]+[(0.67+0.52) * 30$ months $]+[(0.67+0.52+1.13) * 3$ months $]\} *\{50$ provinces $\} *\{30.46$ days per month in the average month in $12 / 2007-12 / 2010\}=69,227$ additional births. This corresponds to 1.90 additional months of births, given that the average number of births per month in Spain prior to the policy $(01 / 2000-11 / 2007)$ was 36,514 . 
Accordingly, $€ 1,000$ in benefits would have had an effect of $1-2 \%$ on fertility, not far from Milligan's (2005) estimate of 2.6\%. ${ }^{35}$

Cohen, Dehejia, and Romanov (2013) find that a 1\% reduction in the "price" of children leads to a $0.5 \%$ increase in fertility in Israel, whereas Milligan (2005) observes a $0.1 \%$ increase in Canada. The Spanish benefit was equivalent to about $15 \%$ of the cost of raising a child during the first 3 years of life (Save the Children 2018). Our results thus suggest that a $1 \%$ decline in the price of children led to a $0.2 \%$ increase in fertility, while the corresponding price increase reduced fertility by $0.4 \%$.

\section{Conclusions}

We assess the effects of the introduction of a universal child benefit, and its later cancellation, on fertility behavior in Spain, both through conceptions and abortions. Unique administrative data on births as well as abortions, including information on the basic socio-economic characteristics of the parents, allow us to conduct heterogeneity analyses. We test for the presence of expected discontinuous responses in birth rates at specific points in time following the benefit's introduction and then its cancellation, showing that both announcement and implementation affected fertility. As abortions can react immediately, we use an RD-DiD setup with previous years as controls, thus netting out seasonality in abortion rates. We find that the positive fertility response to the benefit's introduction in 2007 was smaller in magnitude than the fertility decline that occurred after the benefit's cancellation in 2010. Exploiting heterogeneity in economic conditions across provinces, we find that the larger negative effect of the cancellation was particularly pronounced in regions most affected by the economic crisis.

${ }^{35} \mathrm{C} \$ 1,000$ in 1990 is close to the real value of $€ 1,000$ in 2007. 
While previous work has looked at the effects of similar policies on fertility, the use of microdata on abortions to conduct such an analysis is rare in the literature. Our study is also novel in that it explores potential asymmetry in the fertility response to the introduction and then cancellation of the benefit. Crucially, our findings highlight the importance of generous child subsidies as a policy tool for increasing birth rates in low-fertility countries such as Spain. Similar types of interventions could be worth considering for other places struggling with low or declining fertility. 


\section{References}

Baughman, R., and S. Dickert-Conlin. 2003. "Did expanding the EITC promote motherhood?" American Economic Review 93(2): 247-251.

Baughman, R., and S. Dickert-Conlin. 2009. "The Earned Income Tax Credit and fertility." Journal of Population Economics 22(3): 537-563.

Becker, G. 1960. "An economic analysis of fertility." In Demographic and Economic Change in Developed Countries, ed. G. Becker, 209-240. Columbia University Press.

Black, D. A., N. Kolesnikova, S. G. Sanders, and L. J. Taylor. 2013. "Are Children "Normal”?" Review of Economics and Statistics 95(1): 21-33.

Borra, C., L. González, and A. Sevilla. 2019. "The Impact of Scheduling Birth Early on Infant Health." Journal of the European Economic Association 17(1): 30-78.

Brewer, M., A. Ratcliffe, and S. Smith. 2012. "Does welfare reform affect fertility? Evidence from the UK." Journal of Population Economics 25(1): 245-266.

Christelis, D., D. Georgarakos, T. Jappelli, L. Pistaferri, and M. van Rooij. 2019. "Asymmetric Consumption Effects of Transitory Income Shocks.” Economic Journal 129(622): 23222341.

Cohen A., R. Dehejia, and D. Romanov. 2013. "Financial Incentives and Fertility." The Review of Economics and Statistics 95(1): 1-20.

Cygan-Rehm, K. 2016. "Parental leave benefit and differential fertility responses: Evidence from a German reform." Journal of Population Economics 29(1): 73-103.

El Mundo. 2010. "La corta vida del cheque-bebé." May 12, 2010. https://www.elmundo.es/elmundo/2010/05/12/espana/1273650734.html (accessed August $25,2020)$.

El País. 2007a. "La ayuda de 2500 euros por nacimiento de hijo se pagará a partir de diciembre." July 14, 2007. https://elpais.com/diario/2007/07/14/espana/1184364015_850215.html (accessed August 25, 2020).

El País. 2007b. "El Congreso aprueba el cheque-bebé." October 18, 2007. https://elpais.com/elpais/2007/10/18/actualidad/1192695432_850215.html (accessed August 25, 2020).

Farré, L., and L. González. 2019. "Does paternity leave reduce fertility?" Journal of Public Economics 172: 52-66.

González, L. 2013. "The Effect of a Universal Child Benefit on Conceptions, Abortions, and Early Maternal Labor Supply.” American Economic Journal: Economic Policy 5(3): 160-188.

INE (Instituto Nacional de Estadística - Spanish Statistical Office). 2019. "Estadística de partos, 2000-2017." Microdata. 
Kearney, M. 2004. "Is there an effect of incremental welfare benefits on fertility behavior? A look at the family cap." Journal of Human Resources 39(2): 295-325.

La Vanguardia. 2007. "El cheque-bebé podría empezarse a aplicar a partir del 1 de julio.” October 2 , 2007.) https://www.lavanguardia.com/politica/20071002/53398642235/el-chequebebe-podria-empezarse-a-aplicar-a-partir-del-1-de-julio.html (accessed August 25, 2020).

Lalive, R., and J. Zweimüller. 2009. "How does parental leave affect fertility and return to work? Evidence from two natural experiments." The Quarterly Journal of Economics 124(3): 1363-1402.

Lindo, J. 2010. “Are Children Really Inferior Goods? Evidence from Displacement-driven Income Shocks." Journal of Human Resources, 45(2): 301-327.

Lovenheim, M. F., and K. J. Mumford. 2013. "Do Family Wealth Shocks Affect Fertility Choices? Evidence from the Housing Market." Review of Economics and Statistics 95(2): 464-475.

Malkova, O. 2018. "Can Maternity Benefits Have Long-Term Effects on Childbearing? Evidence from Soviet Russia." Review of Economics and Statistics 100(4): 691-703.

Meghir, C., and L. Pistaferri. 2011. "Earnings, Consumption and Life Cycle Choices." In Handbook of Labor Economics, Volume 4b, Handbooks in Economics, eds. O. Ashenfelter, and D. Card, 773-854. Great Britain: North Holland.

Milligan, K. 2005. "Subsidizing the Stork: New Evidence on Tax Incentives and Fertility." Review of Economics and Statistics 87(3): 539-555.

MSCBS (Ministerio de Sanidad, Consumo y Bienestar Social - Ministry of Health, Consumer Affairs and Social Welfare). 2019. "Estadística de interrupciones voluntarias del embarazo, 2000-2017." Microdata.

Moffitt, R. 1998. "The effect of welfare on marriage and fertility." In Welfare, the family, and reproductive behavior: research perspectives: 50-98. National Academies Press.

OECD Family Database, 2019. "Public spending on family benefits." http://www.oecd.org/els/family/ database.htm (accessed in January 2019).

Olivetti, C., and B. Petrongolo. 2017. "The Economic Consequences of Family Policies: Lessons from a Century of Legislation in High-Income Countries." Journal of Economic Perspectives 31(1): 205-230.

Price, J. 2013. "How Income Affects Fertility." Institute for Family Studies (IFS) blog. https://ifstudies.org/blog/how-income-affects-fertility (accessed December 2020).

Raute, A. 2019. "Can financial incentives reduce the baby gap? Evidence from a reform in maternity leave benefits.” Journal of Public Economics 169: 203-222.

Riphahn, R., and F. Wiynck. 2017. "Fertility effects of child benefits." Journal of Population Economics 30(4): 1135-1184.

Rosenzweig, M. 1999. "Welfare, marital prospects, and nonmarital childbearing." Journal of Political Economy 107(6): 3-32. 
RTVE. 2010. "José Luis Rodríguez Zapatero dice adiós al cheque-bebé, su medida estrella en política social.” May 12, 2010. https://www.rtve.es/noticias/20100512/jose-luis-rodriguezzapatero-dice-adios-cheque-bebe-su-medida-estrella-politica-social/331041.shtml (accessed August 25, 2020).

Save the Children. 2018. "El coste de la crianza." www.savethechildren.es/publicaciones/el-costede-la-crianza (accessed in January 2019).

Schultz, T. P. 2007. "Population Policies, Fertility, Women's Human Capital, and Child Quality." In Handbook of Development Economics, Volume 4, eds. T. P. Schultz, and J. Strauss, eds., 3249-3303. Amsterdam: North-Holland, Elsevier.

UNFPA (United Nations Population Fund). 2018. "The State of World Population 2018. The power of choice: Reproductive rights and the demographic transition." https://esaro.unfpa.org/en/publications/power-choice-reproductive-rights-anddemographic-transition (accessed in December 2020). 


\section{Figures}

Figure 1: Timeline of the universal child benefit policy and its expected effects on birth rates

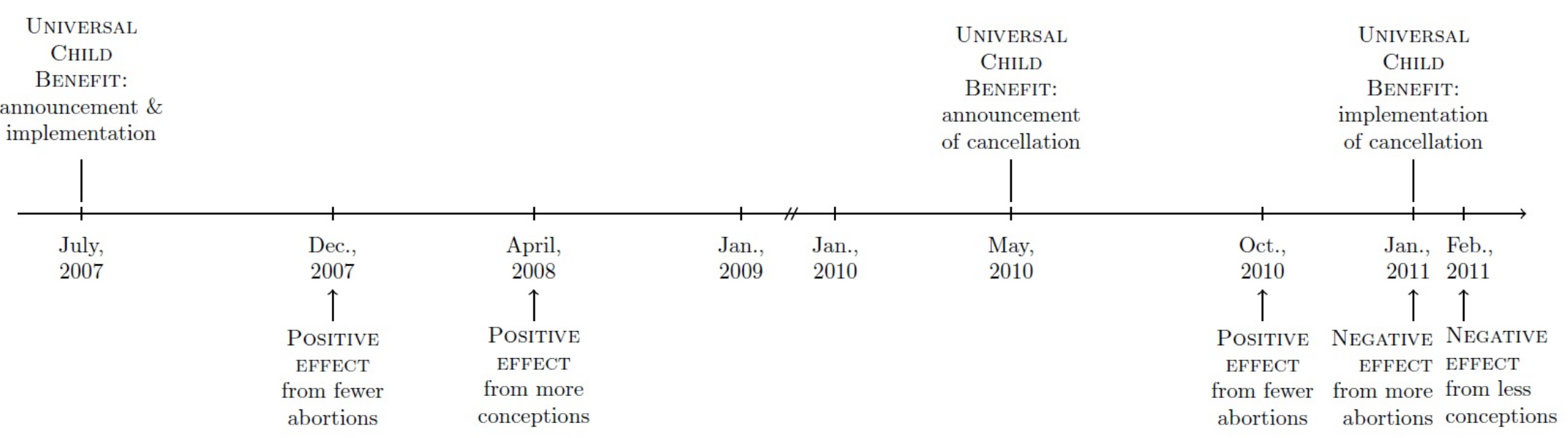


Figure 2: Birth and abortion rates in Spain, 2000-2017

a) Birth rates

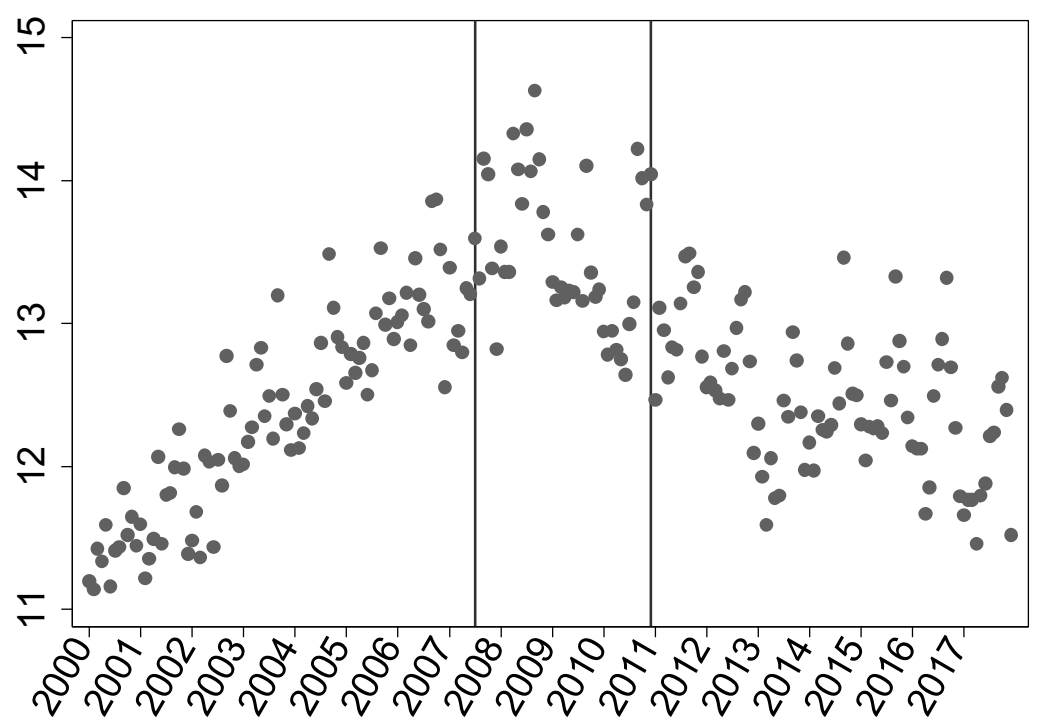

b) Abortion rates

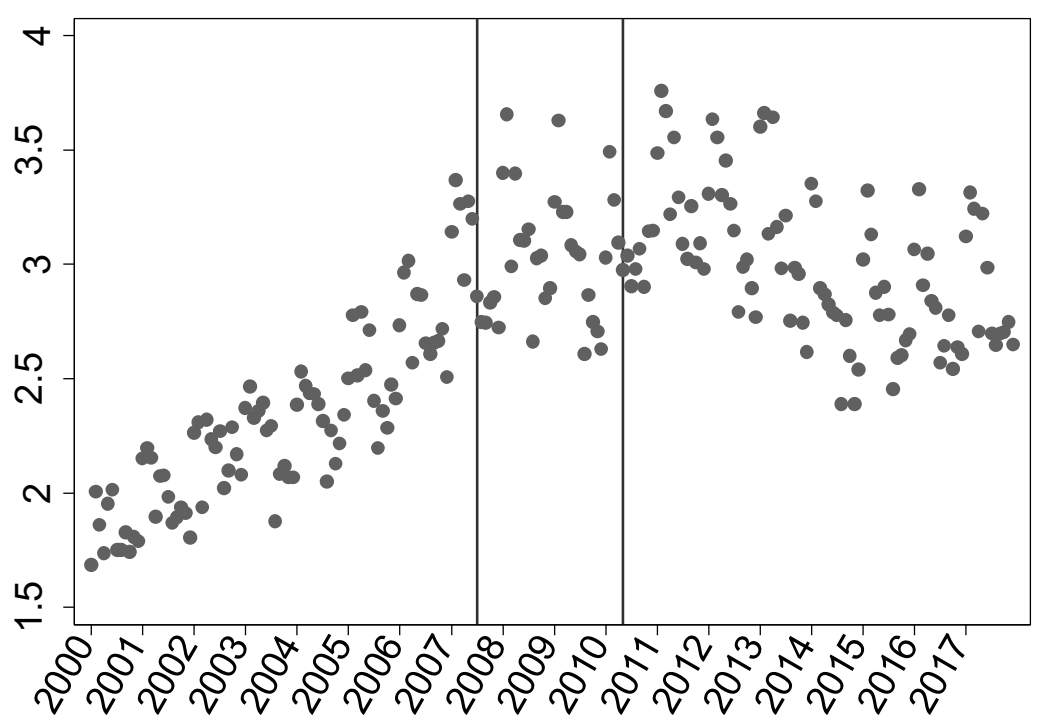

Notes: Birth/abortion rate per day per 100,000 women aged 15-44. The birth/abortion rate is calculated as the number of births/abortions per day to women of reproductive age (15-44 years), divided by the number of women of reproductive age, in each calendar month between January 2000 and December 2017, and expressed per 100,000 women of reproductive age. January of each year is marked on the x-axis. The vertical lines in the left graph mark the start (July 2007) and end (December 2010) of the universal child benefit policy; the vertical lines in the right graph mark the announcement of its introduction (July 2007) and that of its cancellation (May 2010). 
Figure 3: Birth rates in Spain, 2000-2017, by calendar month

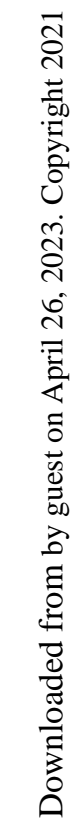

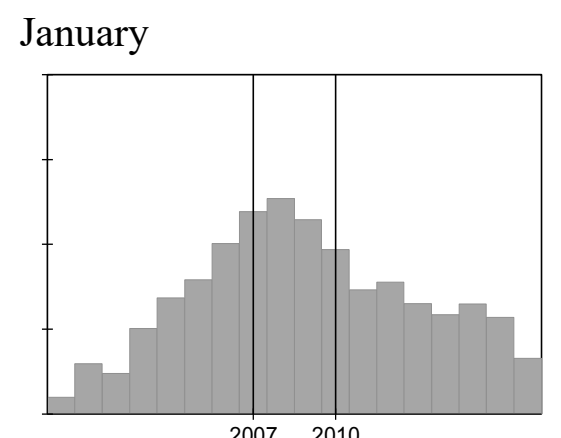

May

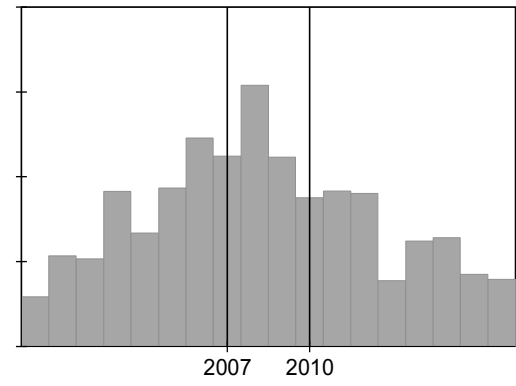

September

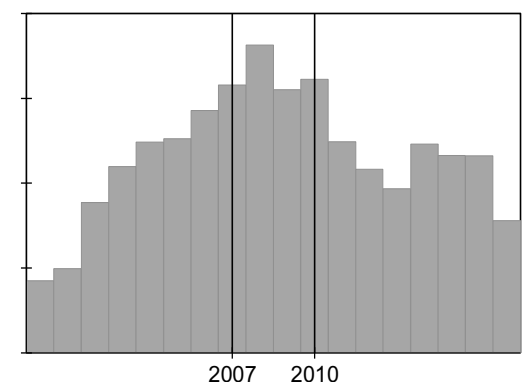

February

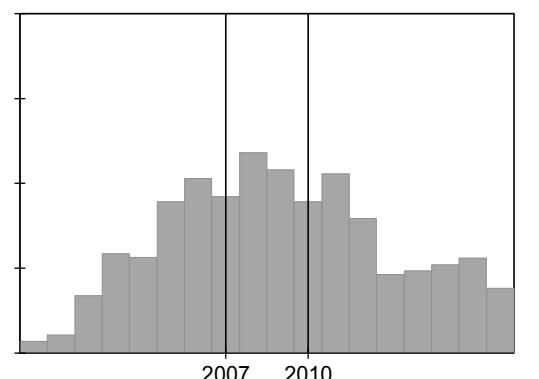

June

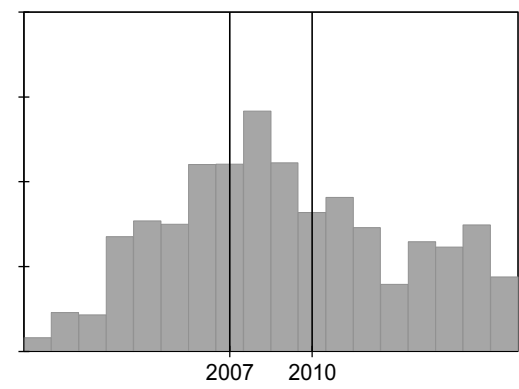

October

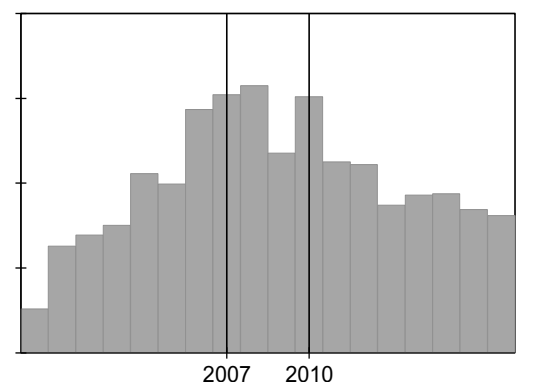

March

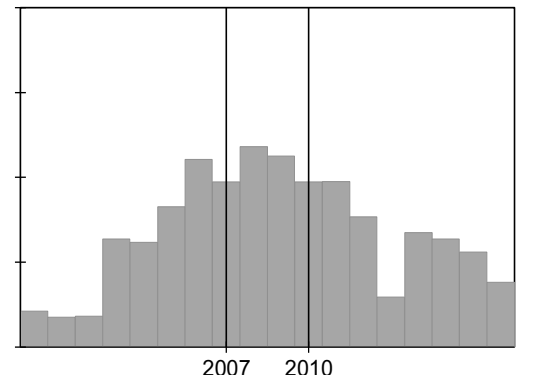

July

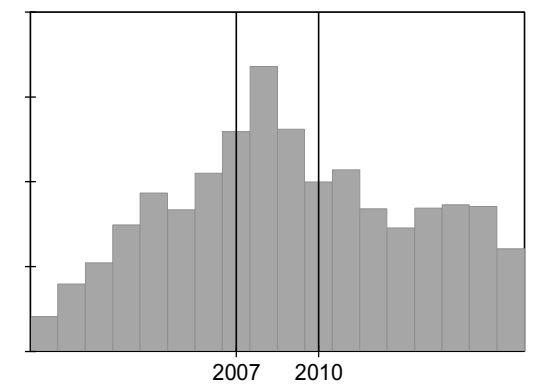

November

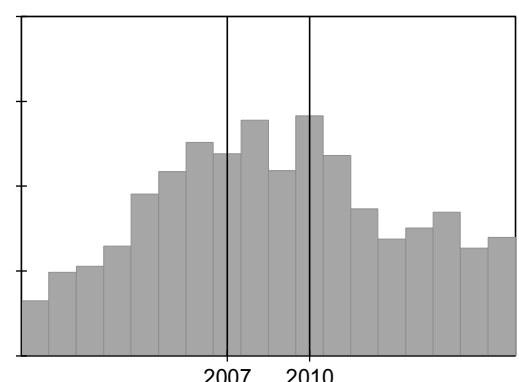

April

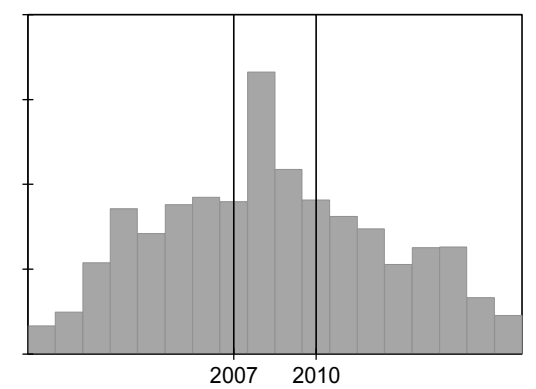

August

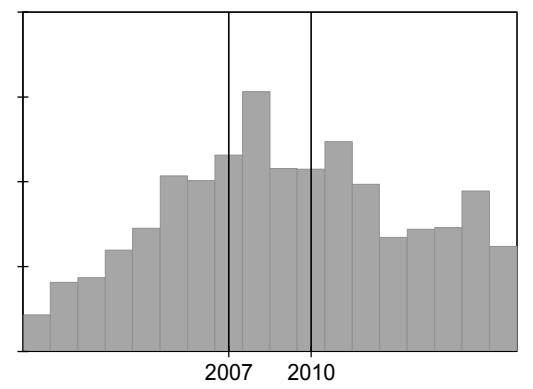

December

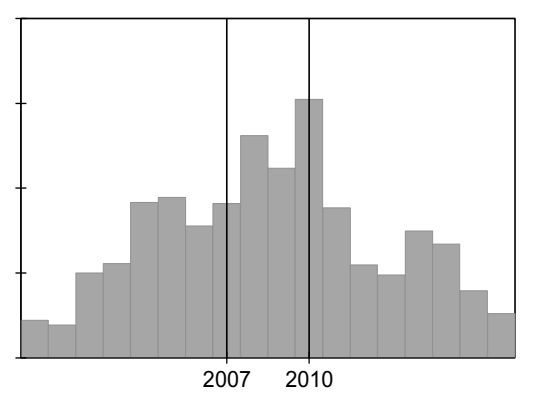

Notes: Birth rate per day per 100,000 women aged 15-44, calculated as in Figure 2. The range of the y-axis is 11-15; all graphs are on the same scale. Year is shown on the $\mathrm{x}$-axis; period covered is 2000-2017. 
Figure 4: Birth rates in Spain during universal child benefit policy

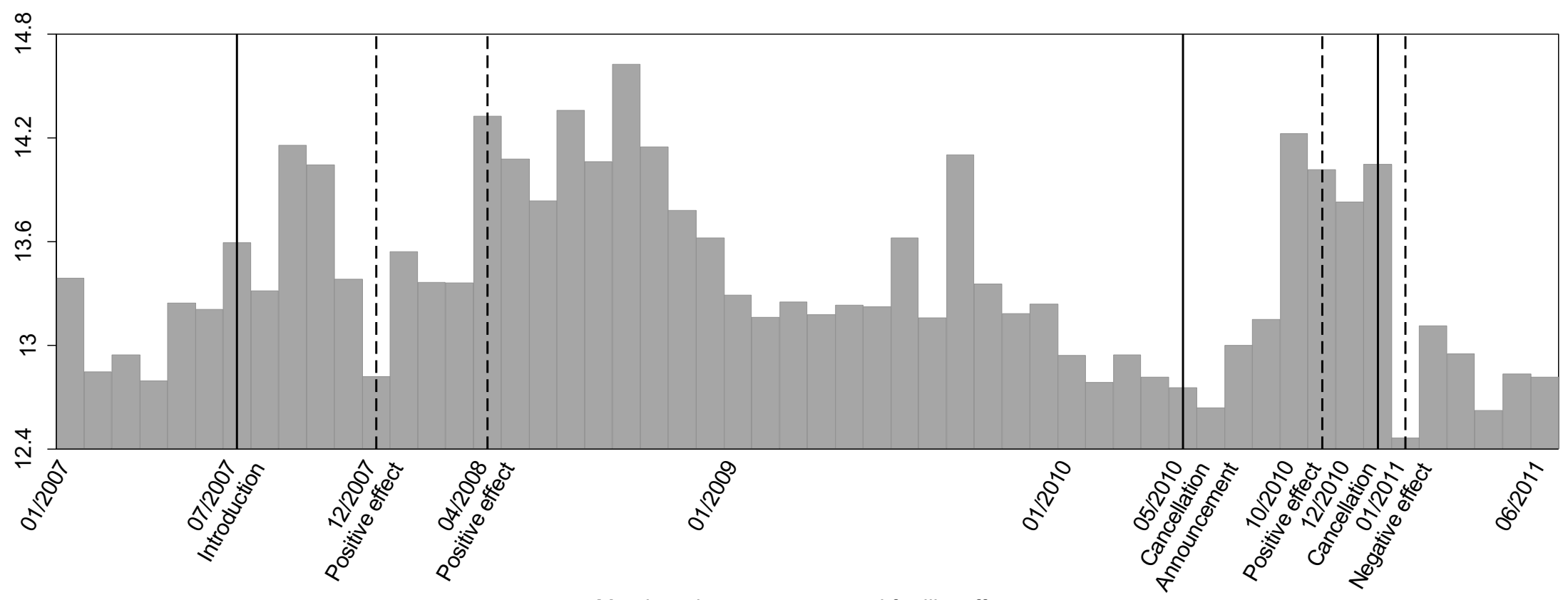

Month and event or expected fertility effect

Notes: Birth rate per day per 100,000 women aged 15-44, calculated as in Figure 2. Period covered is January 2007-June 2011. The solid vertical lines mark the start, the announcement of the end, and the end of the universal child benefit policy. The dashed vertical lines mark months when fertility effects of the policy are expected. 
Figure 5: RDD graphs of abortion rates in Spain around the time of child-benefit-related announcements and in preceding years

a) Introduction announcement $(0=$ week starting on July 4$)$
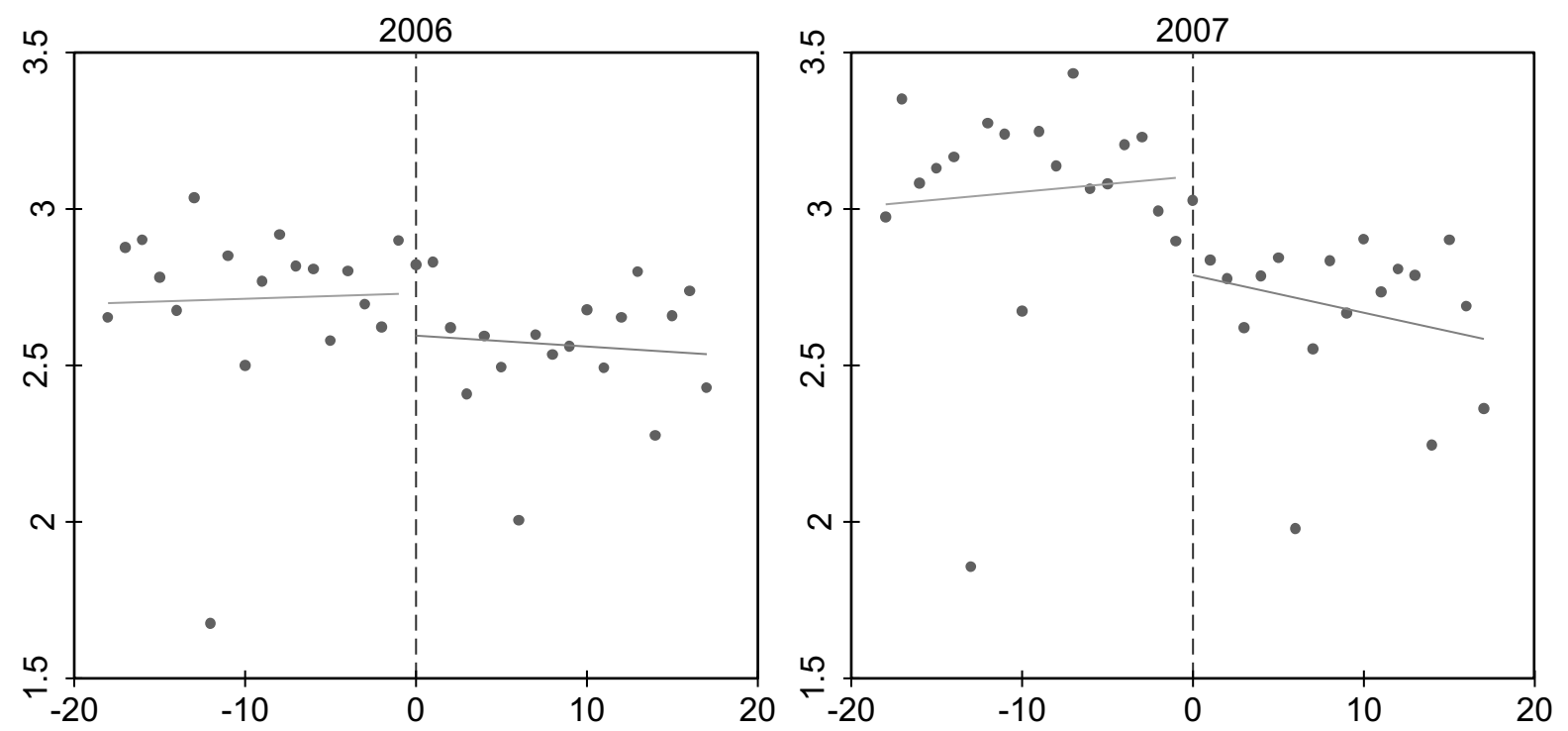

b) Cancellation announcement ( $0=$ week starting on May 13)
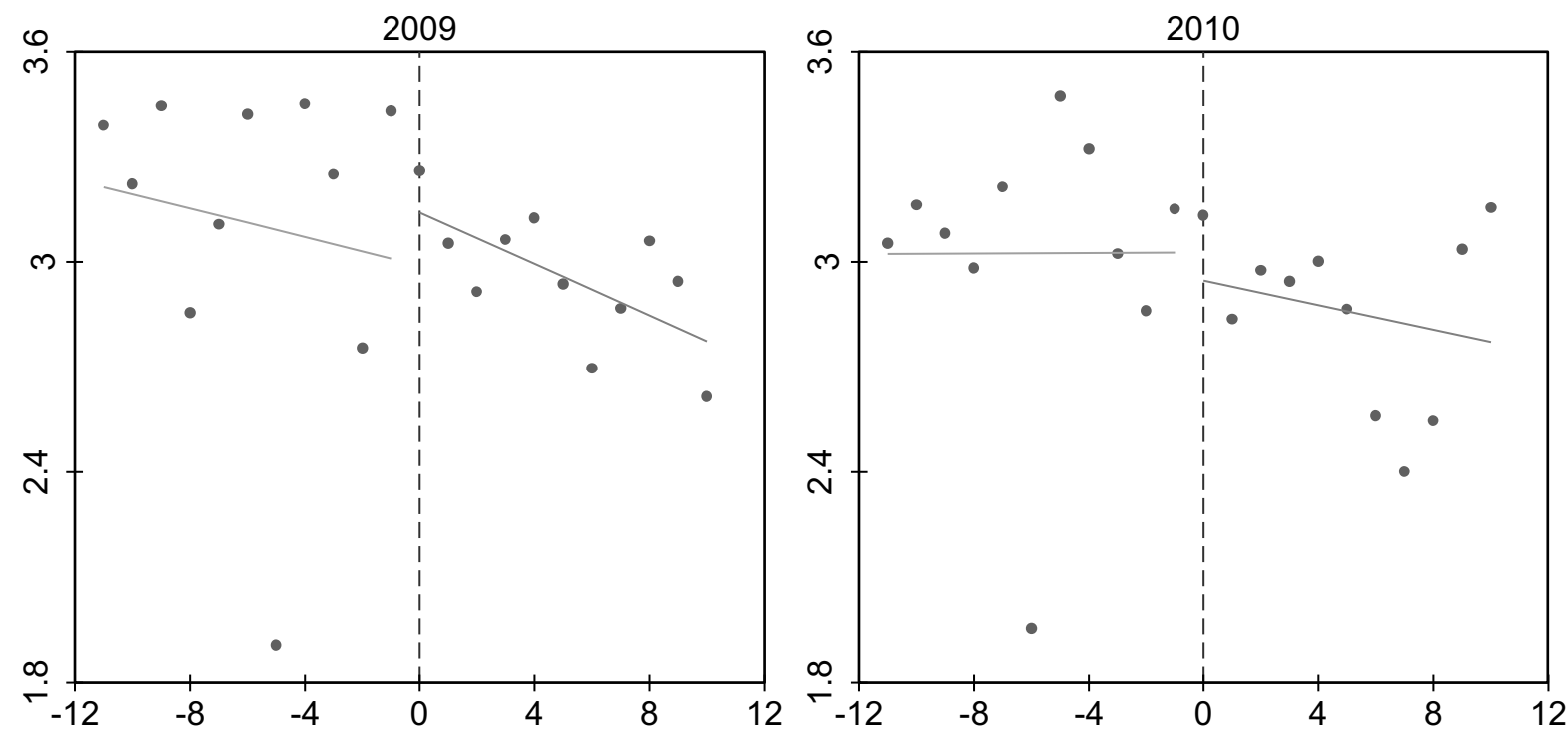

Notes: Abortion rate per day per 100,000 women aged 15-44, calculated as in Table 2. 


\section{Tables}

Table 1: Estimated effects of the universal child benefit on births

\begin{tabular}{|c|c|c|c|c|c|c|}
\hline & (1) & $(2)$ & (3) & (4) & (5) & (6) \\
\hline & $\log$ (births) & $\log$ (births) & $\begin{array}{c}\text { Donut } \\
\text { Log(births) }\end{array}$ & $\begin{array}{c}\text { Donut } \\
\text { Log(births) }\end{array}$ & $\begin{array}{l}\text { Donut } \\
\text { Birth rate }\end{array}$ & $\begin{array}{l}\text { Donut } \\
\text { Births }\end{array}$ \\
\hline $\begin{array}{l}\text { Transition into child benefit } \\
\qquad(12 / 2007-03 / 2008)\end{array}$ & $\begin{array}{l}0.0356^{* * *} \\
(0.0078)\end{array}$ & $\begin{array}{c}0.0347 * * * \\
(0.0075)\end{array}$ & $\begin{array}{c}0.0351 * * * \\
(0.0075)\end{array}$ & $\begin{array}{l}0.0037 \\
(0.0071)\end{array}$ & $\begin{array}{l}0.1187^{*} \\
(0.0701)\end{array}$ & $\begin{array}{c}0.6744^{* * *} \\
(0.1834)\end{array}$ \\
\hline $\begin{array}{l}\text { Child benefit period } \\
\qquad(04 / 2008-09 / 2010)\end{array}$ & $\begin{array}{l}0.0189 * \\
(0.0101)\end{array}$ & $\begin{array}{c}0.0276^{* * *} \\
(0.0077)\end{array}$ & $\begin{array}{c}0.0277 * * * \\
(0.0077)\end{array}$ & $\begin{array}{l}0.0172^{* *} \\
(0.0078)\end{array}$ & $\begin{array}{c}0.2154^{* * *} \\
(0.0759)\end{array}$ & $\begin{array}{c}0.5186^{* * *} \\
(0.1827)\end{array}$ \\
\hline $\begin{array}{l}\text { Transition out of child benefit } \\
\qquad(10 / 2010-12 / 2010)\end{array}$ & $\begin{array}{c}0.0538^{* * *} \\
(0.0094)\end{array}$ & $\begin{array}{c}0.0629 * * * \\
(0.0062)\end{array}$ & $\begin{array}{c}0.0471^{* * *} \\
(0.0075)\end{array}$ & $\begin{array}{c}0.0415^{* * *} \\
(0.0073)\end{array}$ & $\begin{array}{c}0.5273^{* * *} \\
(0.0912)\end{array}$ & $\begin{array}{c}1.1295^{* * *} \\
(0.2371)\end{array}$ \\
\hline $\begin{array}{l}\text { Post-child-benefit period } \\
\qquad(01 / 2011-12 / 2017)\end{array}$ & $\begin{array}{c}-0.0793^{* * *} \\
(0.0070)\end{array}$ & $\begin{array}{c}-0.0740^{* * *} \\
(0.0063)\end{array}$ & $\begin{array}{c}-0.0569 * * * \\
(0.0079)\end{array}$ & $\begin{array}{c}-0.0495 * * * \\
(0.0072)\end{array}$ & $\begin{array}{c}-0.7049 * * * \\
(0.0940)\end{array}$ & $\begin{array}{c}-1.5875 * * * \\
(0.3453)\end{array}$ \\
\hline Employment rate, male & $\begin{array}{l}0.5500^{*} \\
(0.3067)\end{array}$ & $\begin{array}{c}0.4191 * * * \\
(0.1009)\end{array}$ & $\begin{array}{c}0.4205^{* * *} \\
(0.1011)\end{array}$ & $\begin{array}{c}0.0654 \\
(0.0921)\end{array}$ & $\begin{array}{l}1.9841 * \\
(1.0959)\end{array}$ & $\begin{array}{c}13.5033^{* * *} \\
(4.7444)\end{array}$ \\
\hline Unemployment rate, male & $\begin{array}{c}0.0671 \\
(0.2143)\end{array}$ & $\begin{array}{c}-0.1628^{* *} \\
(0.0679)\end{array}$ & $\begin{array}{c}-0.1675^{* *} \\
(0.0677)\end{array}$ & $\begin{array}{c}-0.2875^{* * *} \\
(0.0630)\end{array}$ & $\begin{array}{c}-3.8812 * * * \\
(0.7645)\end{array}$ & $\begin{array}{c}-4.0412^{* *} \\
(1.9271)\end{array}$ \\
\hline $\log ($ women aged 15-44) & & & & $\begin{array}{c}1.4848^{* * *} \\
(0.1310) \\
\end{array}$ & & \\
\hline Month & $\begin{array}{c}0.0194 * * * \\
(0.0013)\end{array}$ & & & & & \\
\hline Month squared & $\begin{array}{c}-0.0000^{* * *} \\
(0.0000)\end{array}$ & & & & & \\
\hline Province-specific month & & YES & YES & YES & YES & YES \\
\hline Province-specific month ${ }^{\wedge} 2$ & & YES & YES & YES & YES & YES \\
\hline Province-specific month ^ 3 & & & & YES & YES & \\
\hline Province FE & YES & YES & YES & YES & YES & YES \\
\hline Calendar month FE & YES & YES & YES & YES & YES & YES \\
\hline Observations & 10,800 & 10,800 & 10,700 & 10,700 & 10,700 & 10,700 \\
\hline R-squared & 0.9920 & 0.9945 & 0.9944 & 0.9947 & 0.8054 & 0.9964 \\
\hline Average $\mathrm{Y}$ in $07 / 2006-06 / 2007$ & \multicolumn{4}{|c|}{25.87} & 12.56 & 25.87 \\
\hline Average $Y$ in $05 / 2009-04 / 2010$ & \multicolumn{4}{|c|}{26.03} & 12.73 & 26.03 \\
\hline
\end{tabular}

Notes: OLS regressions. Monthly data on the 50 Spanish provinces between 01/2000 and 12/2017.

Dependent variables are: logarithm of number of births per day in each calendar month among women aged 15-44 years (columns 1-4); the corresponding birth rate, expressed per 100,000 women aged 15-44 years (column 5); and number of births per day in each calendar month among women aged 15-44 years (column 6). In columns 3-6, births in 12/2010 and 01/2011 are set to missing. Column 5 is our preferred specification. (Un)employment rates are included with a lag of three quarters. Standard errors are clustered at the province level. 
Table 2: Treatment effects of the universal child benefit on abortions

\begin{tabular}{|l|c|c|c|}
\hline \multirow{2}{*}{$\begin{array}{c}\text { Panel A: Dependent variable } \\
\text { Log(abortions) }\end{array}$} & July 4, 2007 & May 13, 2010 & August 1, 2010 \\
\cline { 2 - 4 } & $(1)$ & $(2)$ & $(3)$ \\
\hline Treatment & $\mathbf{- 0 . 0 4 9 5}$ & $\mathbf{- 0 . 2 1 7 7 * * *}$ & $\mathbf{0 . 1 8 5 4 * * *}$ \\
& $\mathbf{( 0 . 0 5 0 2 )}$ & $\mathbf{( 0 . 0 6 5 0 )}$ & $\mathbf{( 0 . 0 5 7 3 )}$ \\
\hline Week FE & YES & YES & YES \\
Year FE & YES & YES & YES \\
Province FE & YES & YES & YES \\
\hline Observations & 1,600 & 1,600 & 1,600 \\
R-squared & 0.8564 & 0.8670 & 0.8850 \\
\hline Average Y in 07/2006-06/2007 & \multicolumn{3}{|c|}{5.54} \\
Average Y in 05/2009-04/2010 & \multicolumn{3}{|c|}{5.65} \\
\hline Panel B: Dependent variable & July 4,2007 & May 13, 2010 & August 1,2010 \\
\cline { 2 - 4 } Abortion rate & $(1)$ & $(2)$ & $(3)$ \\
\hline Treatment & $\mathbf{- 0 . 1 5 3 8 * *}$ & $\mathbf{- 0 . 1 4 9 5 * *}$ & $\mathbf{0 . 3 6 5 3 * * *}$ \\
& $\mathbf{( 0 . 0 6 2 1 )}$ & $\mathbf{( 0 . 0 6 5 6 )}$ & $\mathbf{( 0 . 0 8 5 2 )}$ \\
\hline Week FE & YES & YES & YES \\
Year FE & YES & YES & YES \\
Province FE & YES & YES & YES \\
\hline Observations & 1,600 & 1,600 & 1,600 \\
R-squared & 0.7201 & 0.7145 & 0.6325 \\
\hline Average Y in $07 / 2006-06 / 2007$ & \multicolumn{3}{|c}{2.29} \\
Average Y in $05 / 2009-04 / 2010$ & \multicolumn{3}{|c|}{} \\
\hline
\end{tabular}

Notes: Estimates of discontinuity at the cut-off in an RD-DiD framework. Weekly data on the 50 Spanish provinces in the year of announcement (treatment year) and in the preceding year (control year). Dependent variables are logarithm of number of abortions per day in each week among women aged 15-44 years (panel A) and the corresponding abortion rate, expressed per 100,000 women aged 15-44 years (panel B). Forcing variable is the week of abortion; weeks are created such that they start on July 4 (column 1), May 13 (column 2), and August 1 (column 3). Data are restricted to 8 weeks on each side of the cut-off. Data in column 3 cover 8 weeks prior to May 13 on the left side of the cut-off (i.e., March 14 to May 8) in order to exclude the problematic period of May 13-July 31. Abortions related to fetal deformations are excluded from the sample. Standard errors are clustered at the province level. 
Table 3: Heterogeneity analysis of births by parents' socio-demographic and occupational characteristics

\begin{tabular}{|c|c|c|c|}
\hline \multirow[b]{3}{*}{$\begin{array}{l}\text { Dependent variable: } \\
\text { Log(Births) }\end{array}$} & $(1)$ & (2) & (3) \\
\hline & Age & Marital status & Skills \\
\hline & $\begin{array}{l}\text { Mother older } \\
\text { vs. younger }\end{array}$ & $\begin{array}{l}\text { Mother married } \\
\text { vs. not married }\end{array}$ & $\begin{array}{l}\text { At least one } \\
\text { parent high- } \\
\text { skilled vs. none } \\
\text { high-skilled }\end{array}$ \\
\hline \multicolumn{4}{|l|}{ Main effects: } \\
\hline $\begin{array}{l}\text { Transition into child benefit } \\
\qquad(12 / 2007-03 / 2008)\end{array}$ & $\begin{array}{c}0.0125 \\
(0.0080)\end{array}$ & $\begin{array}{c}0.0090 \\
(0.0094)\end{array}$ & $\begin{array}{c}0.1303^{* * *} \\
(0.0192)\end{array}$ \\
\hline Child benefit period & $0.0461 * * *$ & $0.0229 * *$ & $0.0542^{* * *}$ \\
\hline$(04 / 2008-09 / 2010)$ & $(0.0091)$ & $(0.0096)$ & $(0.0132)$ \\
\hline Transition out of child benefit & $0.0653^{* * *}$ & $0.0432^{* * *}$ & 0.0145 \\
\hline$(10 / 2010-12 / 2010)$ & $(0.0110)$ & $(0.0086)$ & $(0.0106)$ \\
\hline Post-child-benefit period & $-0.0296 * * *$ & $-0.0508 * * *$ & $0.0198 *$ \\
\hline$(01 / 2011-12 / 2017)$ & $(0.0102)$ & $(0.0099)$ & $(0.0105)$ \\
\hline \multicolumn{4}{|l|}{ Interacted terms: } \\
\hline Transition into child benefit & $0.0412^{* * *}$ & $0.0717 * * *$ & $-0.2178^{* * *}$ \\
\hline$(12 / 2007-03 / 2008)$ & $(0.0100)$ & $(0.0153)$ & $(0.0337)$ \\
\hline Child benefit period & $-0.0310^{* * *}$ & 0.0049 & $-0.0730 * * *$ \\
\hline$(04 / 2008-09 / 2010)$ & $(0.0077)$ & $(0.0128)$ & $(0.0168)$ \\
\hline Transition out of child benefit & $-0.0313^{* *}$ & 0.0016 & 0.0306 \\
\hline$(10 / 2010-12 / 2010)$ & $(0.0122)$ & $(0.0166)$ & $(0.0229)$ \\
\hline Post-child-benefit period & $-0.0552 * * *$ & -0.0162 & $-0.1675^{* * *}$ \\
\hline$(01 / 2011-12 / 2017)$ & $(0.0108)$ & $(0.0152)$ & $(0.0205)$ \\
\hline Male (un)employment rates & YES & YES & YES \\
\hline Province-specific month & YES & YES & YES \\
\hline Province-specific month ^ 2 & YES & YES & YES \\
\hline Province-specific month ^ 3 & & & YES \\
\hline Province FE & YES & YES & YES \\
\hline Calendar month FE & YES & YES & YES \\
\hline Observations & 21,400 & 21,400 & 21,400 \\
\hline R-squared & 0.9909 & 0.9898 & 0.9859 \\
\hline Average $\mathrm{Y}$ in $07 / 2006-06 / 2007$ Reference & 10.26 & 18.22 & 11.12 \\
\hline Average $\mathrm{Y}$ in $07 / 2006-06 / 2007$ Interacted & 15.61 & 7.65 & 14.75 \\
\hline Average $\mathrm{Y}$ in $05 / 2009-04 / 2010$ Reference & 11.43 & 16.93 & 13.54 \\
\hline Average $\mathrm{Y}$ in $05 / 2009-04 / 2010$ Interacted & 14.60 & 9.10 & 12.49 \\
\hline
\end{tabular}

Notes: OLS regressions. Monthly data on the 50 Spanish provinces between 01/2000 and 12/2017. Dependent variable is logarithm of number of births per day in each calendar month among women aged 15-44 years in the specific subgroup. Fully interacted model: all variables are interacted with dummy variable "younger," "not married," and "no parent is high-skilled" in columns 1-3, respectively, and the dummy variable itself is also included. Division into younger (15-32 years) 
and older (33-44 years) age groups in column 1 is based on median maternal age in 2000-2017. Category "not-high-skilled" includes low-skilled individuals and those out of the labor force. Births in 12/2010 and 01/2011 are set to missing. (Un)employment rates are included with a lag of three quarters. Standard errors are clustered at the province level. 
Table 4: Heterogeneity analysis of abortions by woman's socio-demographic and educational characteristics

\begin{tabular}{|c|c|c|c|c|c|}
\hline \multirow[b]{2}{*}{$\begin{array}{l}\text { Dependent variable: } \\
\operatorname{Log(Abortions)}\end{array}$} & $(1)$ & $(2)$ & (3) & (4) & $(5)$ \\
\hline & $\begin{array}{l}\text { Mother older } \\
\text { vs. younger }\end{array}$ & $\begin{array}{l}\text { Mother married } \\
\text { vs. not married }\end{array}$ & $\begin{array}{l}\text { Mother at least } \\
\text { high school vs. } \\
\text { less than high } \\
\text { school }\end{array}$ & $\begin{array}{c}\text { Richer province } \\
\text { vs. poorer } \\
\text { province }\end{array}$ & $\begin{array}{l}\text { Lighter crisis vs. } \\
\text { stronger crisis }\end{array}$ \\
\hline Post-July-4-2007 & $\begin{array}{l}-0.0885 \\
(0.1114)\end{array}$ & $\begin{array}{l}-0.1298 \\
(0.1146)\end{array}$ & $\begin{array}{l}-0.1350 \\
(0.0835)\end{array}$ & $\begin{array}{l}-0.0121 \\
(0.0290)\end{array}$ & $\begin{array}{c}0.0098 \\
(0.0385)\end{array}$ \\
\hline Interaction & $\begin{array}{r}0.0056 \\
(0.1443) \\
\end{array}$ & $\begin{array}{r}0.0999 \\
(0.1480) \\
\end{array}$ & $\begin{array}{r}0.0342 \\
(0.1135) \\
\end{array}$ & $\begin{array}{l}-0.0253 \\
(0.0506) \\
\end{array}$ & $\begin{array}{l}-0.0691 \\
(0.0497) \\
\end{array}$ \\
\hline Post-May-13-2010 & $\begin{array}{c}-0.2416^{* *} \\
(0.1014)\end{array}$ & $\begin{array}{l}-0.1821 \\
(0.1182)\end{array}$ & $\begin{array}{l}-0.1000 \\
(0.0916)\end{array}$ & $\begin{array}{l}-0.0754 \\
(0.0489)\end{array}$ & $\begin{array}{c}-0.1341 * * \\
(0.0626)\end{array}$ \\
\hline Interaction & $\begin{array}{c}0.0256 \\
(0.1275) \\
\end{array}$ & $\begin{array}{l}-0.0456 \\
(0.1339)\end{array}$ & $\begin{array}{l}-0.1236 \\
(0.0993)\end{array}$ & $\begin{array}{l}-0.0669 \\
(0.0717)\end{array}$ & $\begin{array}{c}0.0505 \\
(0.0720) \\
\end{array}$ \\
\hline Post-August-1-2010 & $\begin{array}{c}0.1705 \\
(0.1170)\end{array}$ & $\begin{array}{c}0.3717 * * * \\
(0.1145)\end{array}$ & $\begin{array}{c}0.1422^{* *} \\
(0.0636)\end{array}$ & $\begin{array}{c}0.1272^{* * *} \\
(0.0401)\end{array}$ & $\begin{array}{l}0.1093^{* *} \\
(0.0496)\end{array}$ \\
\hline Interaction & $\begin{array}{c}0.0371 \\
(0.1459) \\
\end{array}$ & $\begin{array}{c}-0.2371 * \\
(0.1261) \\
\end{array}$ & $\begin{array}{c}0.1197 \\
(0.1043) \\
\end{array}$ & $\begin{array}{l}-0.0690 \\
(0.0626) \\
\end{array}$ & $\begin{array}{l}-0.0332 \\
(0.0632) \\
\end{array}$ \\
\hline Week FE & YES & YES & YES & YES & YES \\
\hline Year FE & YES & YES & YES & YES & YES \\
\hline Province FE & YES & YES & YES & YES & YES \\
\hline Average $\mathrm{Y}$ in $07 / 2006-06 / 2007$ Reference & 1.28 & 1.26 & 2.33 & 3.60 & 2.82 \\
\hline Average $\mathrm{Y}$ in $07 / 2006-06 / 2007$ Interaction & 4.26 & 4.24 & 3.17 & 1.95 & 2.72 \\
\hline Average Y in 05/2009-04/2010 Reference & 1.45 & 1.22 & 2.29 & 3.51 & 2.88 \\
\hline Average Y in 05/2009-04/2010 Interaction & 4.20 & 4.40 & 3.32 & 2.14 & 2.77 \\
\hline
\end{tabular}

Notes: Estimates of discontinuity at the cut-off in an RD-DiD framework. Estimations equivalent to those in Table 2 but on data from different subsamples. Fully interacted model: all variables are interacted with dummy variable "younger," "not married," "less than high school," "poor province," and "stronger crisis" in columns 1-5, respectively, and the dummy variable itself is also included. Division into younger (15-32 years) and older (33-44 years) age groups in column 1 is based on median maternal age in birth data in $2000-2017$. 
Data are restricted to 8 weeks on each side of the cut-off. Abortions related to fetal deformations are excluded. Sample size is 3,200. Standard errors are clustered at the province level. 
Table 5: Estimated effects of the universal child benefit on births by economic conditions in the province

\begin{tabular}{|c|c|c|c|c|}
\hline \multirow{3}{*}{$\begin{array}{l}\text { Economic conditions indicator } \\
\text { Dependent variable }\end{array}$} & \multicolumn{2}{|c|}{ Income level } & \multicolumn{2}{|c|}{ Economic crisis intensity } \\
\hline & $(1)$ & $(2)$ & (3) & (4) \\
\hline & Log(births) & Birth rate & Log(births) & Birth rate \\
\hline \multicolumn{5}{|l|}{ Main effects: } \\
\hline $\begin{array}{l}\text { Transition into child benefit } \\
\qquad(12 / 2007-03 / 2008)\end{array}$ & $\begin{array}{c}0.0387 * * * \\
(0.0066)\end{array}$ & $\begin{array}{l}0.1579 * * \\
(0.0709)\end{array}$ & $\begin{array}{c}0.0380^{* * *} \\
(0.0075)\end{array}$ & $\begin{array}{l}0.1523^{*} \\
(0.0763)\end{array}$ \\
\hline Child benefit period & $0.0247 * * *$ & $0.2615^{* * *}$ & $0.0325^{* * *}$ & $0.2900^{* * *}$ \\
\hline$(04 / 2008-09 / 2010)$ & $(0.0062)$ & $(0.0791)$ & $(0.0057)$ & $(0.0625)$ \\
\hline Transition out of child benefit & $0.0279 * * *$ & $0.3430^{* * *}$ & $0.0231 * *$ & $0.2201 *$ \\
\hline$(10 / 2010-12 / 2010)$ & $(0.0102)$ & $(0.1241)$ & $(0.0104)$ & $(0.1236)$ \\
\hline Post-child-benefit period & $-0.0419 * * *$ & $-0.4972 * * *$ & $-0.0265^{* *}$ & $-0.3024 * *$ \\
\hline$(01 / 2011-12 / 2017)$ & $(0.0128)$ & $(0.1508)$ & $(0.0115)$ & $(0.1342)$ \\
\hline \multicolumn{5}{|l|}{ Interaction with economic indicators: } \\
\hline Transition into child benefit & -0.0073 & -0.0795 & -0.0055 & -0.0625 \\
\hline$(12 / 2007-03 / 2008)$ & $(0.0143)$ & $(0.1271)$ & $(0.0143)$ & $(0.1271)$ \\
\hline Child benefit period & 0.0067 & -0.0916 & -0.0125 & -0.1522 \\
\hline$(04 / 2008-09 / 2010)$ & $(0.0168)$ & $(0.1645)$ & $(0.0167)$ & $(0.1614)$ \\
\hline Transition out of child benefit & $0.0389 * *$ & $0.3688^{*}$ & $0.0449 * * *$ & $0.6107 * * *$ \\
\hline$(10 / 2010-12 / 2010)$ & $(0.0155)$ & $(0.2077)$ & $(0.0147)$ & $(0.1934)$ \\
\hline Post-child-benefit period & -0.0298 & $-0.4155^{*}$ & $-0.0627 * * *$ & $-0.8061 * * *$ \\
\hline$(01 / 2011-12 / 2017)$ & $(0.0190)$ & $(0.2229)$ & $(0.0174)$ & $(0.2007)$ \\
\hline Employment rate, male & $0.4104 * * *$ & $1.9352^{*}$ & $0.4256^{* * *}$ & $2.0316^{*}$ \\
\hline \multirow[t]{2}{*}{ Unemployment rate, male } & $-0.1791 * *$ & $-3.9284^{* * *}$ & $-0.1416^{* *}$ & $-3.7983^{* * *}$ \\
\hline & $(0.0722)$ & $(0.7754)$ & $(0.0665)$ & $(0.7496)$ \\
\hline Province-specific month & YES & YES & YES & YES \\
\hline Province-specific month $\wedge 2$ & YES & YES & YES & YES \\
\hline Province-specific month $\wedge 3$ & & YES & & YES \\
\hline Province FE & YES & YES & YES & YES \\
\hline Calendar month FE & YES & YES & YES & YES \\
\hline Observations & 10,700 & 10,700 & 10,700 & 10,700 \\
\hline R-squared & 0.9945 & 0.8056 & 0.9945 & 0.8059 \\
\hline Average $\mathrm{Y}$ in $07 / 2006-06 / 2007$ better off & 25.24 & 11.88 & 30.81 & 12.68 \\
\hline Average $\mathrm{Y}$ in $07 / 2006-06 / 2007$ worse off & 26.50 & 13.25 & 20.93 & 12.45 \\
\hline Average $\mathrm{Y}$ in $05 / 2009-04 / 2010$ better off & 25.92 & 12.41 & 31.34 & 13.01 \\
\hline Average $\mathrm{Y}$ in $05 / 2009-04 / 2010$ worse off & 26.13 & 13.05 & 20.71 & 12.46 \\
\hline
\end{tabular}

Notes: OLS regressions. Monthly data on the 50 Spanish provinces between 01/2000 and 12/2017. Dependent variables are logarithm of number of births per day in each calendar month among women aged 15-44 years (columns 1 and 3) and the corresponding birth rate, expressed per 100,000 women aged 15-44 years (columns 2 and 4). Columns 1-2 show interaction terms with a 
dummy variable that takes a value of 1 for the 25 provinces with lower GDP p.c. in 2007 and 2010, and 0 otherwise. The dummy variable is also included in the model but not shown. Columns 3-4 show interaction terms with a dummy variable that takes a value of 1 for the 25 provinces more affected by the economic crisis, and 0 otherwise. Births in 12/2010 and 01/2011 are set to missing. (Un)employment rates are included with a lag of three quarters. Standard errors are clustered at the province level. 
Table 6: Heterogeneity analysis of births by parity

\begin{tabular}{|c|c|c|c|c|c|}
\hline \multirow{2}{*}{$\begin{array}{c}\text { Dependent variable: } \\
\text { Log(Births) }\end{array}$} & $(1)$ & $(2)$ & (3) & $(4)$ & $(5)$ \\
\hline & Firstborn & $\begin{array}{l}\text { Higher } \\
\text { parity }\end{array}$ & $\begin{array}{c}\text { Second } \\
\text { born }\end{array}$ & Third born & Parity 4+ \\
\hline Transition into child benefit & 0.0044 & $0.0834 * * *$ & $0.0840 * * *$ & $0.0919 * * *$ & $0.1048^{* *}$ \\
\hline$(12 / 2007-03 / 2008)$ & $(0.0107)$ & $(0.0180)$ & $(0.0194)$ & $(0.0251)$ & $(0.0410)$ \\
\hline Child benefit period & $0.0266^{* *}$ & $0.0292 * * *$ & $0.0244 * * *$ & 0.0190 & $0.0860 * *$ \\
\hline$(04 / 2008-09 / 2010)$ & $(0.0100)$ & $(0.0088)$ & $(0.0089)$ & $(0.0244)$ & $(0.0373)$ \\
\hline Transition out of child benefit & $0.0216^{* *}$ & $0.0767 * * *$ & $0.0811 * * *$ & 0.0533 & 0.0592 \\
\hline$(10 / 2010-12 / 2010)$ & $(0.0093)$ & $(0.0102)$ & $(0.0105)$ & $(0.0327)$ & $(0.0568)$ \\
\hline Post-child-benefit period & $-0.0352^{* * *}$ & $-0.0821 * * *$ & $-0.0748^{* * *}$ & $-0.0916^{* * *}$ & $-0.1609 * * *$ \\
\hline$(01 / 2011-12 / 2017)$ & $(0.0102)$ & $(0.0094)$ & $(0.0103)$ & $(0.0285)$ & $(0.0440)$ \\
\hline Male (un)employment rates & YES & YES & YES & YES & YES \\
\hline Province-specific month & YES & YES & YES & YES & YES \\
\hline Province-specific month ${ }^{\wedge} 2$ & YES & YES & YES & YES & YES \\
\hline Province-specific month ${ }^{\wedge} 3$ & & & & & \\
\hline Province FE & YES & YES & YES & YES & YES \\
\hline Calendar month FE & YES & YES & YES & YES & YES \\
\hline Observations & 10,700 & 10,700 & 10,700 & 10,700 & 10,700 \\
\hline R-squared & 0.9907 & 0.9869 & 0.9842 & 0.9383 & 0.8503 \\
\hline Average $\mathrm{Y}$ in $07 / 2006-06 / 2007$ & 14.61 & 11.26 & 8.87 & 1.81 & 0.58 \\
\hline Average $\mathrm{Y}$ in $05 / 2009-04 / 2010$ & 14.24 & 11.78 & 9.23 & 1.90 & 0.66 \\
\hline
\end{tabular}

Notes: OLS regressions. Monthly data on the 50 Spanish provinces between 01/2000 and 12/2017. Dependent variable is the logarithm of number of births per day in each calendar month among women aged 15-44 years. Births in 12/2010 and 01/2011 are set to missing. (Un)employment rates are included with a lag of three quarters. Standard errors are clustered at the province level. 
Table 7: Estimated effects of the universal child benefit on age-specific birth rates

\begin{tabular}{|c|c|c|c|c|c|c|}
\hline \multirow{2}{*}{$\begin{array}{c}\text { Dependent variable: } \\
\text { Birth rate }\end{array}$} & (1) & (2) & (3) & (4) & (5) & (6) \\
\hline & $15-19$ & $20-24$ & $25-29$ & $30-34$ & $35-39$ & $40-44$ \\
\hline Transition into child benefit & 0.0923 & $0.5844 * * *$ & $0.3777 * *$ & -0.2674 & 0.0484 & 0.0340 \\
\hline$(12 / 2007-03 / 2008)$ & $(0.0752)$ & $(0.1172)$ & $(0.1691)$ & $(0.2174)$ & $(0.1429)$ & $(0.0607)$ \\
\hline Child benefit period & -0.1093 & $0.2444 *$ & 0.0772 & 0.3136 & $0.5600^{* * *}$ & 0.0089 \\
\hline$(04 / 2008-09 / 2010)$ & $(0.0728)$ & $(0.1302)$ & $(0.1463)$ & $(0.1960)$ & $(0.1540)$ & $(0.0589)$ \\
\hline Transition out of child benefit & -0.1048 & 0.2011 & $0.4346^{*}$ & $1.0995^{* * *}$ & $1.0096^{* * *}$ & $0.1481 *$ \\
\hline$(10 / 2010-12 / 2010)$ & $(0.1287)$ & $(0.1330)$ & $(0.2381)$ & $(0.2462)$ & $(0.2324)$ & $(0.0863)$ \\
\hline Post-child-benefit period & $-0.3128 * * *$ & $-1.1820^{* * *}$ & $-1.1468 * * *$ & $-0.8440^{* * *}$ & $-0.6173^{* * *}$ & -0.0525 \\
\hline$(01 / 2011-12 / 2017)$ & $(0.1165)$ & $(0.1657)$ & $(0.2465)$ & $(0.2473)$ & $(0.1991)$ & $(0.0842)$ \\
\hline Male (un)employment rates & YES & YES & YES & YES & YES & YES \\
\hline Province-specific month & YES & YES & YES & YES & YES & YES \\
\hline Province-specific month ^ 2 & YES & YES & YES & YES & YES & YES \\
\hline Province-specific month $` 3$ & YES & YES & YES & YES & & YES \\
\hline Province FE & YES & YES & YES & YES & YES & YES \\
\hline Calendar month FE & YES & YES & YES & YES & YES & YES \\
\hline Observations & 10,700 & 10,700 & 10,700 & 10,700 & 10,700 & 10,700 \\
\hline R-squared & 0.5583 & 0.7494 & 0.7472 & 0.6250 & 0.6850 & 0.5575 \\
\hline Average $\mathrm{Y}$ in $07 / 2006-06 / 2007$ & 3.04 & 8.47 & 16.82 & 25.64 & 14.23 & 2.49 \\
\hline Average $\mathrm{Y}$ in $05 / 2009-04 / 2010$ & 2.93 & 8.80 & 16.47 & 24.79 & 15.51 & 2.93 \\
\hline
\end{tabular}

Notes: OLS regressions. Monthly data on the 50 Spanish provinces between 01/2000 and 12/2017. Dependent variable is the daily birth rate among women in a given age group, expressed per 100,000 women in that age group, in each calendar month. Births in 12/2010 and 01/2011 are set to missing. (Un)employment rates are included with a lag of three quarters. Standard errors are clustered at the province level. 